
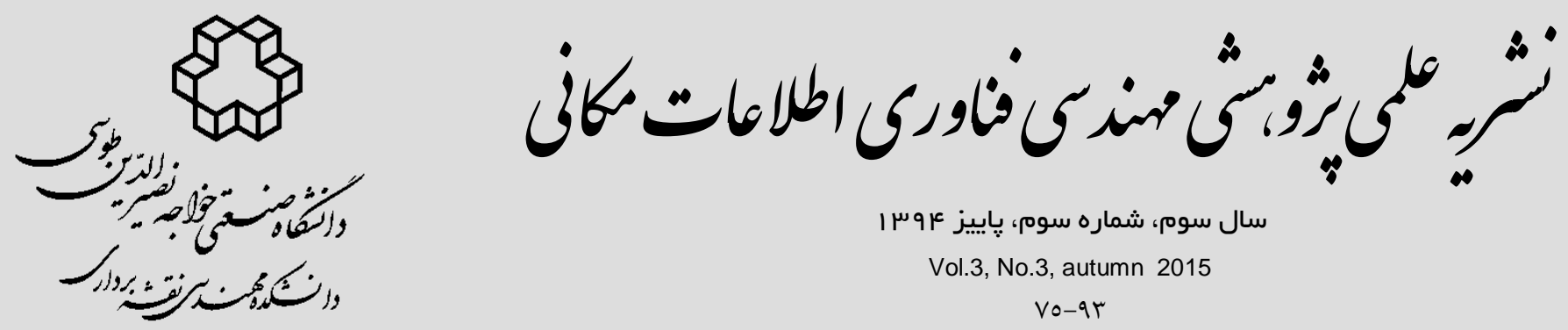

سال سوم، شماره سوم، ياييز ع سر

Vol.3, No.3, autumn 2015

vo-qr

\author{
روشى نوين در تخصيص منابع متحرك بر روى شبكه راه با استفاده از \\ خوشهبندى مكانى -زمانى رويدادها \\ محسن كودرزى '، فرشاد حكيميور "'"، برهام بههلوانى"، سيد محمود حاجى مير رحيمى"

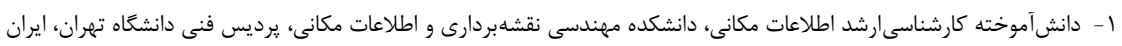

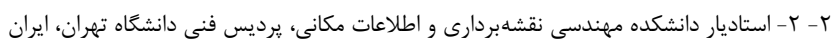

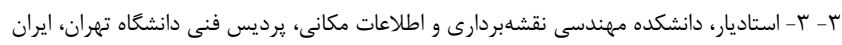

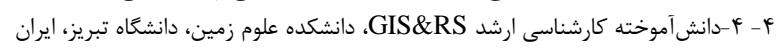

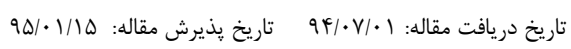

جكيده

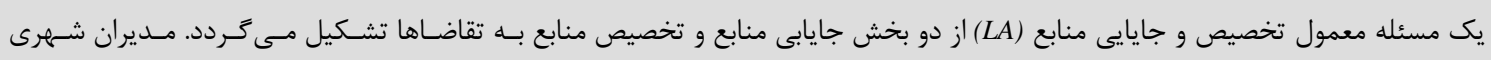

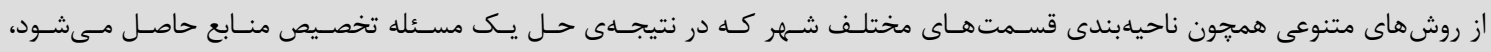

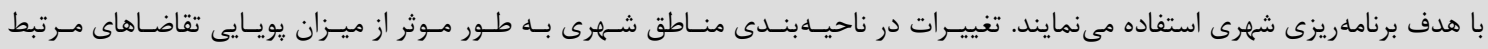

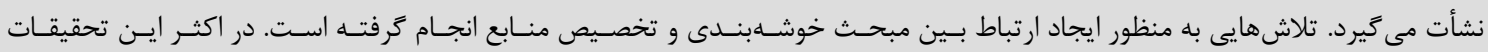

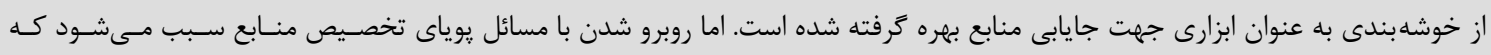

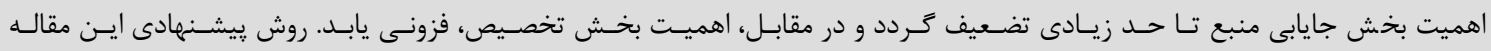

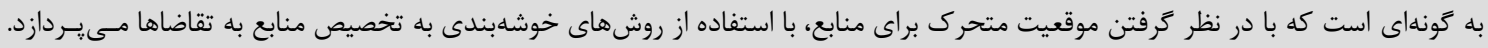

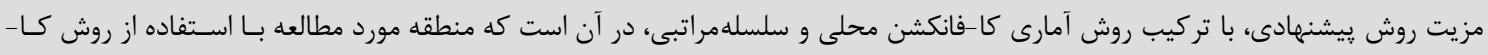

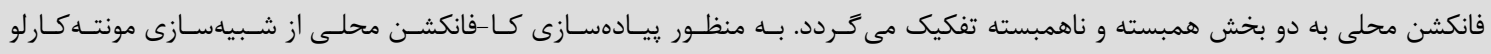

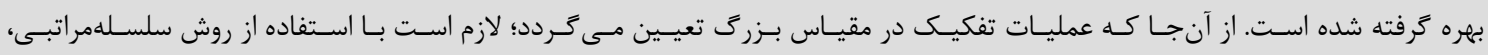

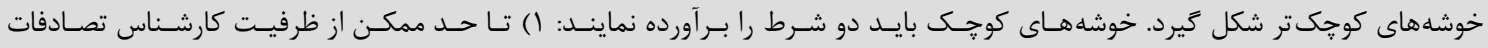

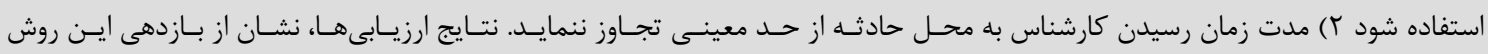

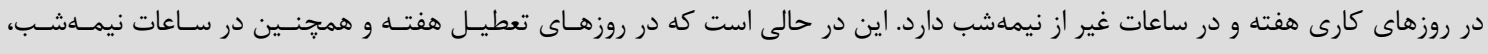

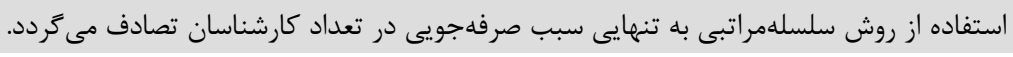

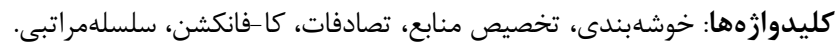

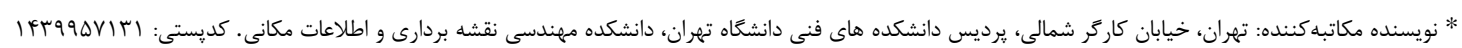
Email: fhakimpour@ut.ac.ir 
نمونههاى متشابه در خوشهاى يكسان قرار كيرند

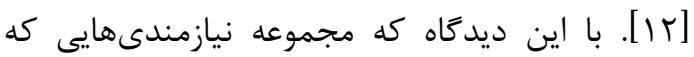

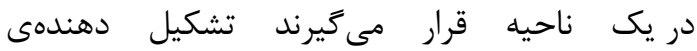
يك خوشه هستند، مسئله تخصيص منابع را مى توان

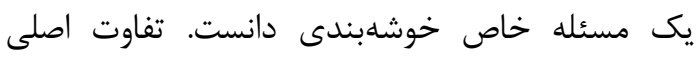
تخصيص منابع و خوشهبندى در تعيين موقعيت منبع

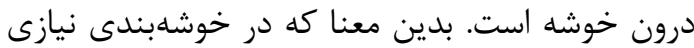

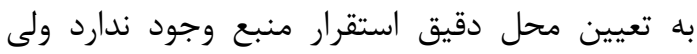
در يك مسئله معمول تخصيص منابع اين كار

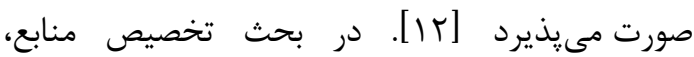
دو دسته منبع وجود دارد: ايستا و متحرك. منبع ايستا همجيون مدرسه و بيمارستان و منبع متحرك مانند كارشناس تصادف و كارشناس يرداخت خسارت سيار بيمه. اكثر سازمانها و شركتهاى فعال در حوزه

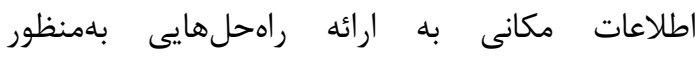

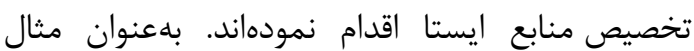

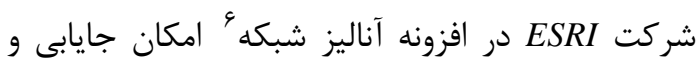

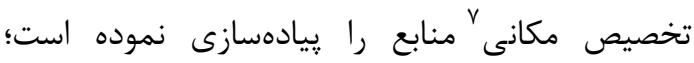

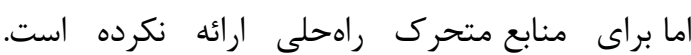

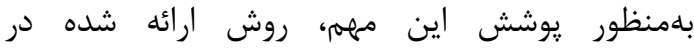
اين تحقيق از خوشهبندى در راستاى تخصيص منابع

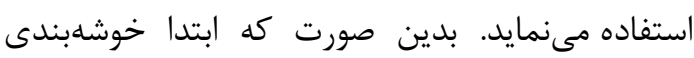
تقاضاهاى مرتبط با منابع متحر ك انجام مىشود. سيس با تعميم خوشهها به شبكه راه از طريق دياكرام ورونوى،

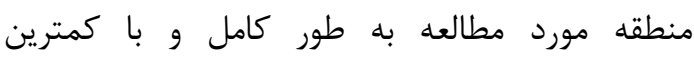
تعداد منبع ناحيهبندى مى مرددد.

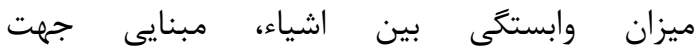

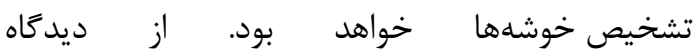

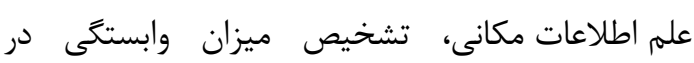
بسيارى از رويدادهاى دنياى واقعى معمولان توانئ تواماً در

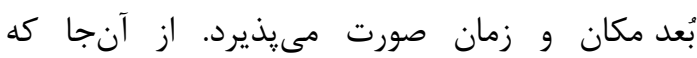

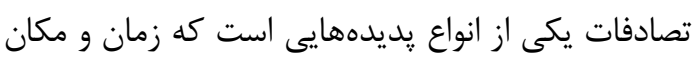

\footnotetext{
${ }^{6}$ Network Analyst Extension
}

${ }^{7}$ Location-Allocation

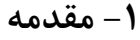

نحوه تخصيص منابع موجود، همواره يكى از جالشهاى مديريت شهرى بوده است. به طور كلى إنى

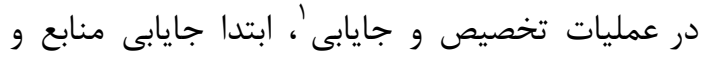

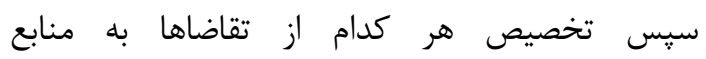
انجام مى يذيرد. تخصيص، فرايندى است كه طى آن آن بخشهايى از شبكه يا مساحتى از محدوده بر اساس فرداس

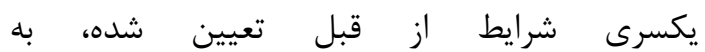
يك مركز خدماتى اختصاص مىيابد [ [1]. به اين فر آيند

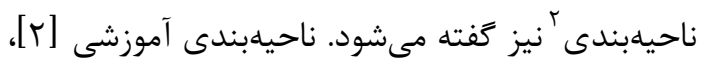

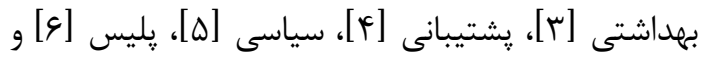

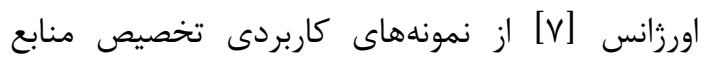

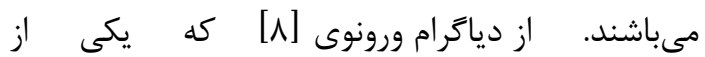

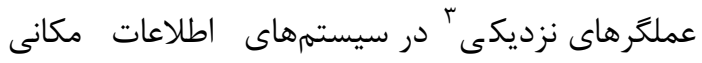

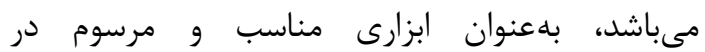
ناحيهبندى استفاده مىشود. از آنجا كه، بسيارى از ازئان

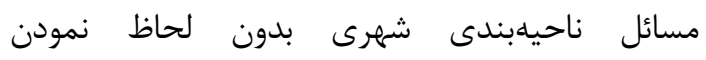
شبكه معابر شهرى قابل حل نبوده و تجزيه و تحليل اين مسائل با فرض اندازهخيرى فاصله اقليدسى ياسخ

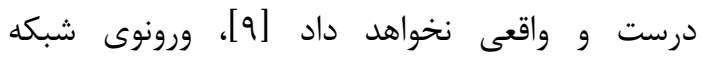
توسعه يافته و در زمينه ناحيهبندى مورد استفاده قرار كرفته است[• ا, 11]. فرايند ناحيهبندى معمولا

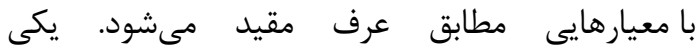

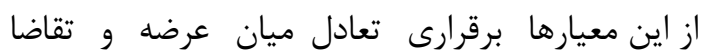
در نواحى مختلف است. علاوه بر آن، نواحى حاصله بايد همجوار "ُ و از لحاظ مكانى متراكمه ه باشند. جهت مشخص نمودن رابطه بين تخصيص منابع و

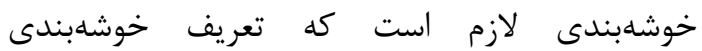
ارائه گَردد. خوشهبندى به فرآيند جداسازى مجموعهاى

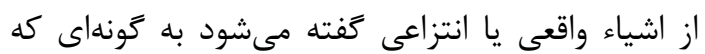

\footnotetext{
${ }^{1}$ Location-Allocation

${ }^{2}$ Districting

${ }^{3}$ Proximity

${ }^{4}$ Contiguous

${ }^{5}$ Compact
} 
مراحل اين تكنيك بدين صورت است كه ابتدا با روش

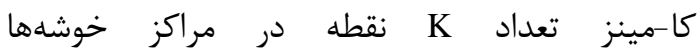

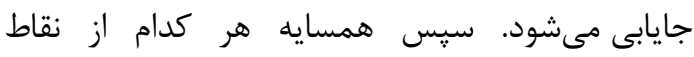

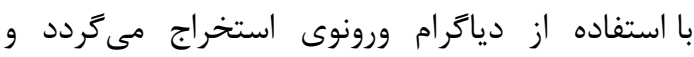

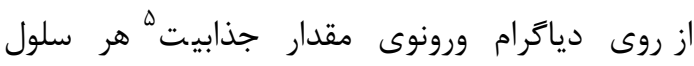
ورونوى بر سلولهاى مجاور محاسبه مىشود. در زيايان

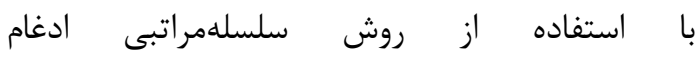

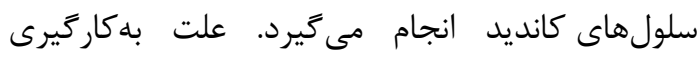

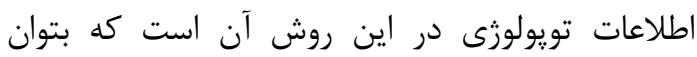
خوشههايى با اشكال مورد نظر را استخر اج كرد.

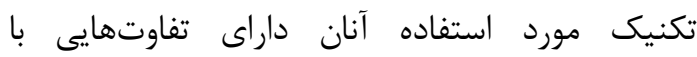
موضوع مطرح در اين مقاله است كه مىتوان بـان به آنها اشاره نمود: - موصوع مطرح

تويولوزى در فضاى صفحه با فضاى شبكه متفاوت است. لذا شكل خوشههاى استخراجى از روى شبكه مشابه صفحه نخواهد بود.

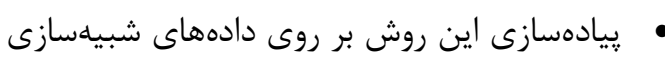

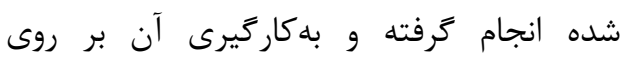
دادهاى واقعى به نظر مشكل مىرسد. • تعداد خوشهها قبل از يردازش بايد تعيين تردد.

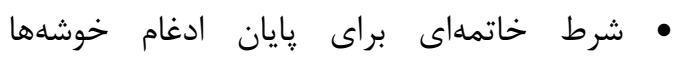
در نظر كرفته نشده است.

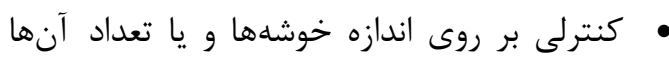

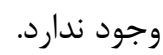

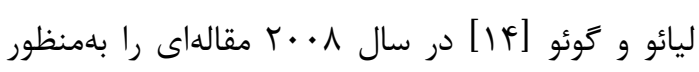

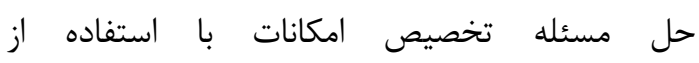
روشهاى خوشهبندى ارائه نمودند. قيد تخصيص منابع

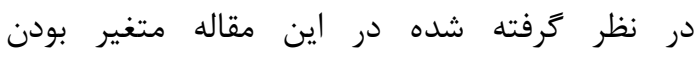

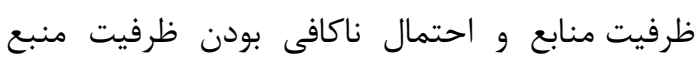

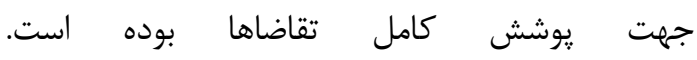
روش بيشنهادى آنان از دو فاز تشكيل مىشد: 1) تخصيص امكانات با ظرفيت متغير به به تقاضاها
آن نقش بسزايى در تحليلهاى مربوطه دارد، تمركز

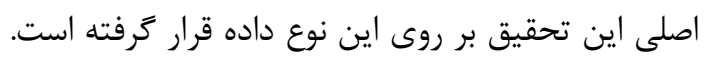

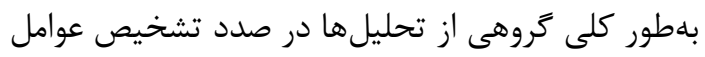
ايجاد تصادفات هستند تا بتوانند نسبت به به برطرف

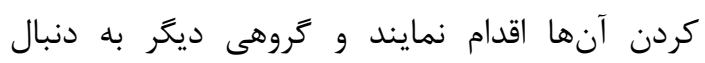

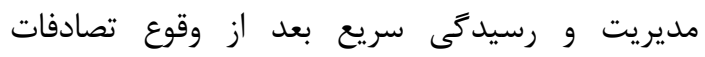
مىباشند. هدف اين تحقيق در راستاى تحليلهاى كروه دوم مىباشد. راهبرد معرفى شده در در اين تحقيق بر روى ري داده

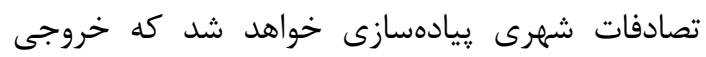

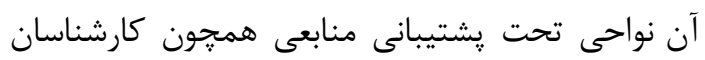

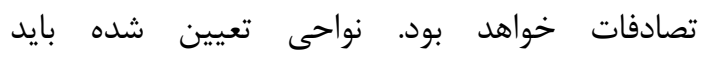

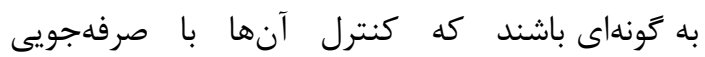

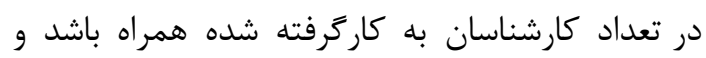

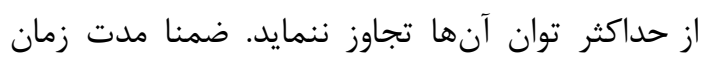

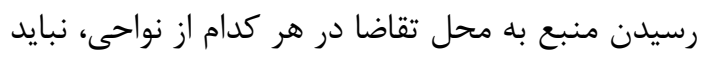
از حد استانداردى فراتر رود.

\section{r- بيشينه تحقيق}

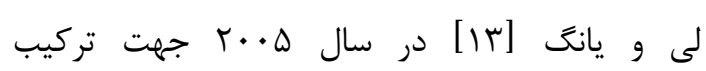

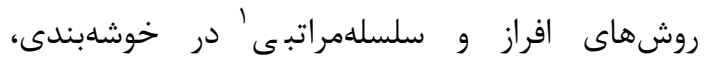

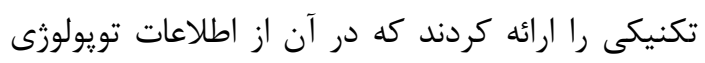

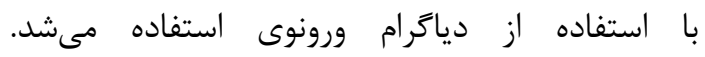

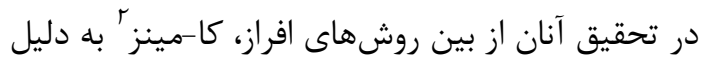

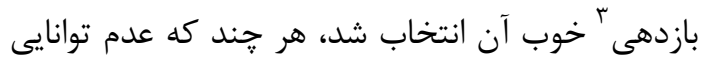
اين روش در كشف خوشههاى غير دايرهاى از معايب آن آن آن آنداب

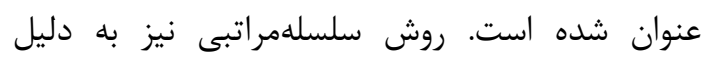

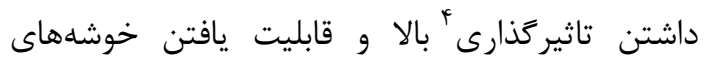

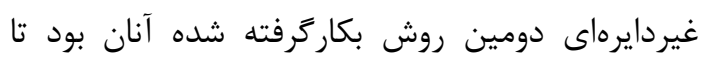

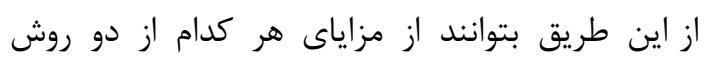

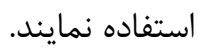

${ }^{1}$ Hierarchical

${ }^{2}$ K-means

${ }^{3}$ Efficiency

${ }^{4}$ Effectiveness 
حذف مى گردند. تمركز اصلى تحقيق انجام گرفته

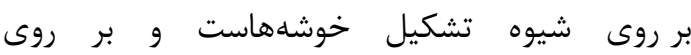

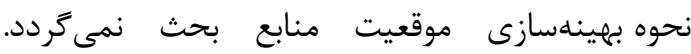
مشكلات اين روش را مى توان سه مورد ذكر كرد: • فاصله اقليدسى در نظر كرفته شده است. • در اين روش تعادل در خوشههاى حاصله به وجود درد

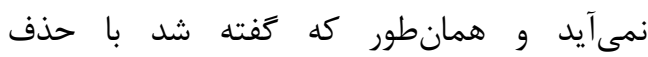
خوشههاى كم ترافيك به نوعى حالت جزيرهاى در منطقه به وجود مى آيد. •رسيدن به تعداد خاص خوشه براى شرط پايان

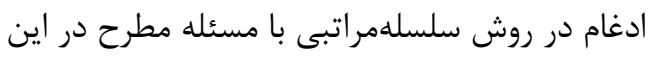
مقاله تطابق ندارد هر هند كه براى مسئله در نظر كرفته شده در مقاله مذكور مناسب بلنظر مىرسد.

\section{r- روش هاى رايج خوشهبندى بر روى شبكه}

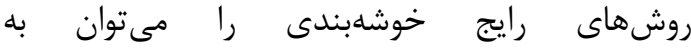

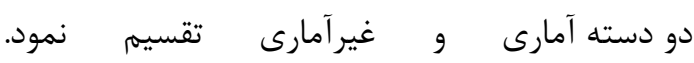

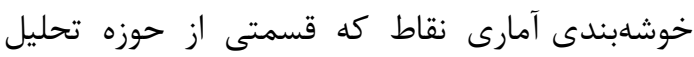

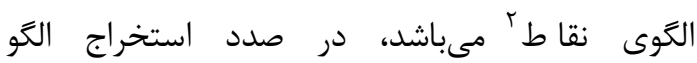

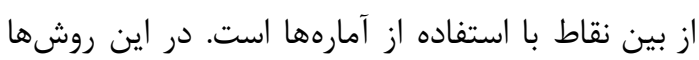

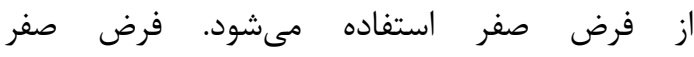

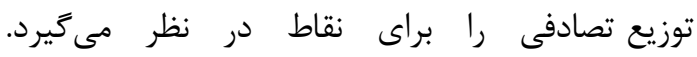
در صورتى كه اين فرض رد شود، نشان از ميل نقاط

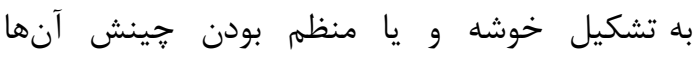
خواهدبود. در تحليل الكَوى نقاط در فضاى دو بعدى،

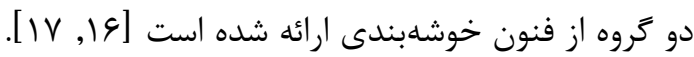

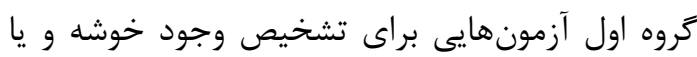

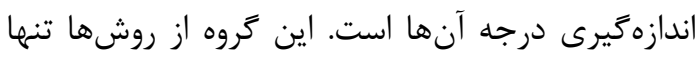
وجود يا عدم وجود تمايل به شكل

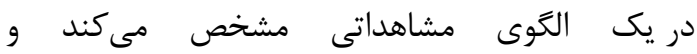
قابليت تعيين موقعيت و اندازه خوشهها را را ندارند.

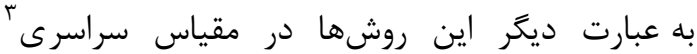

${ }^{2}$ Point Pattern Analysis

${ }^{3}$ Global scale
به كونهاى كه كمترين هزينه را داشته باشد.

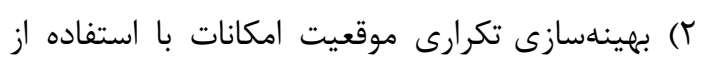
روش خوشهبندى كامينز. اين روش خوشه-مبنا با باريا يك روش هوش مصنوعى با استفاده از تكنيك زنتيك اين روش

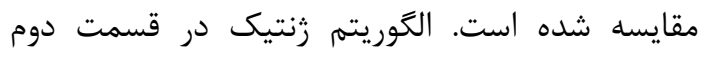

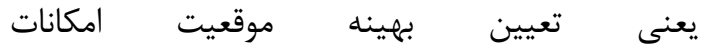

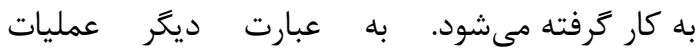

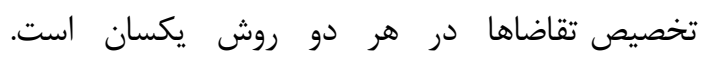
تفاوتهاى اين روش با مسئله مطرح در مقاله بيشرو ران ران مى توان از جند جنبه بيان نمود: • تخصيص تنها براى نقاط تقاضا انجام كرفته است.

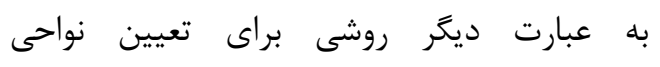
ارائه نشده است. • تعداد منابع قبل از يردازش بايد تعيين گردد. • فاصله اقليدسى در نظر گرفته شده است.

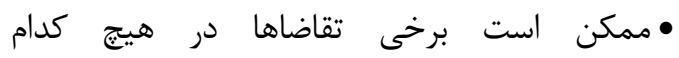
از خوشهها جاى نخيرند.

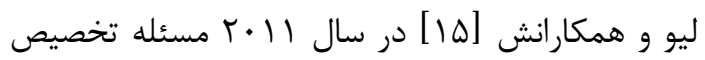

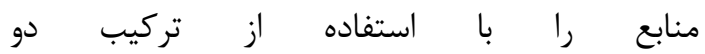

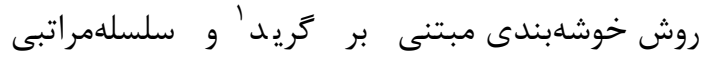

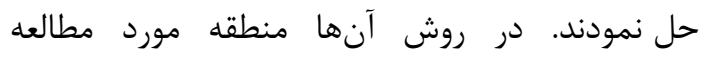

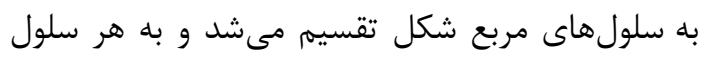
يك بردار سه مولفهاى (x,

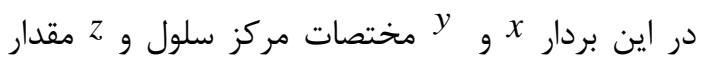

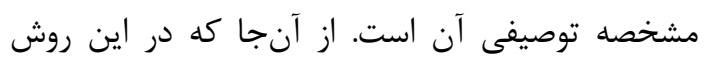

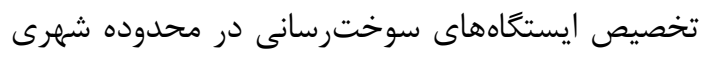
مد نظر بوده است لذا مشخصه توصيفى سلولهان إنا مقدار جريان ترافيك در نظر كرفته شده است. در ادامه با استفاده از روش سلسلهمراتبى، ادغام سلولهاى دراي

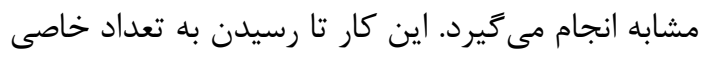

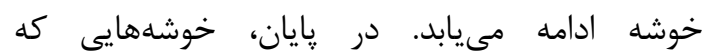

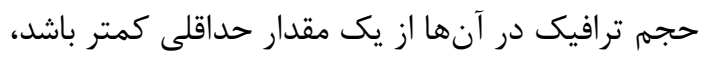

${ }^{1}$ Grid-based 
همكارانش ارائه شد [آr]. در اين روش با اندازمخيرى

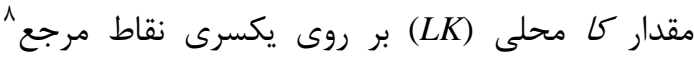

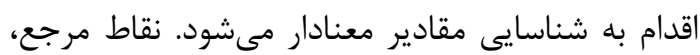

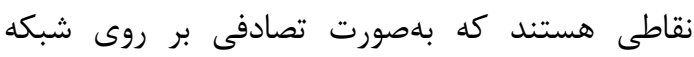

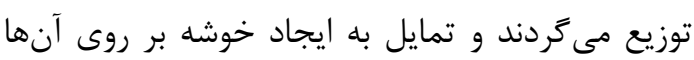
اندازمخيرى مىشود. مجموعه رويدادها، E اميد رياضى و m نشاندهنده تعداد نقاط مرجع توزيعيافته روى شبكه

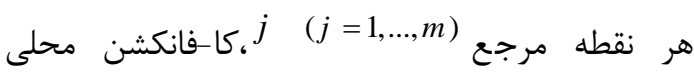
روى شبكه به صورت فرمول (1) تعريف مىشود:

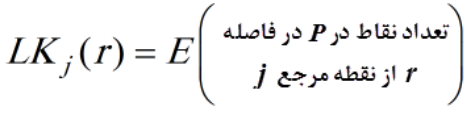

$$
\begin{aligned}
& \text { رابطه (1) }
\end{aligned}
$$$$
r \geq 0 \quad j=1, \ldots, m
$$$$
\text { اكر }
$$$$
\text { تابع شناساگر به صورت فرمول (r) تعريف شود: }
$$

$I_{r}(d(i, j))= \begin{cases}1 & \text { if } d(i, j) \leq r \\ 0 & \text { Otherwise }\end{cases}$

(r) (r)

برآوردكننده نقاط مشاهداتى از طريق فرمول (r)

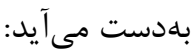

$$
\text { رابطه (س) }
$$

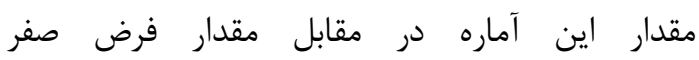

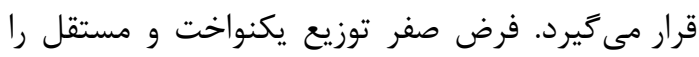
براى رويدادها انتظار دارد. از آنجا كه توزيع دوجملهاي

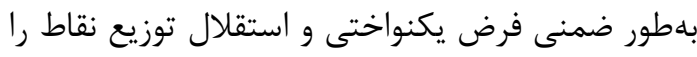

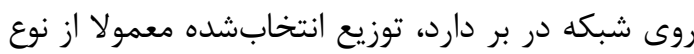

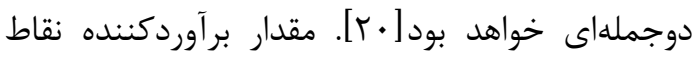
شبيهسازى شده را با با در صورتى كه

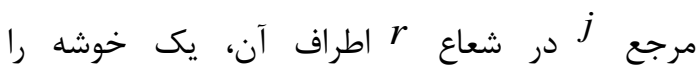

\footnotetext{
${ }^{7}$ Yamada

${ }^{8}$ Reference points
}

كار مى كنند. دومين كروه شامل روشهايى است كه

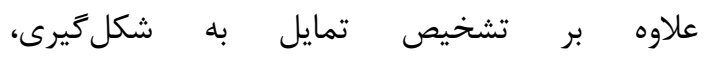

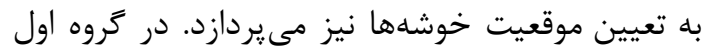

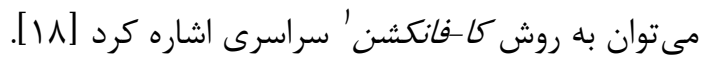

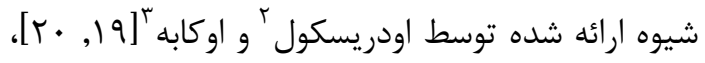
باعث تعميم روش كا-فانكشن روى شبكه شد. از اواخر

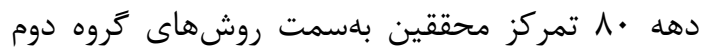

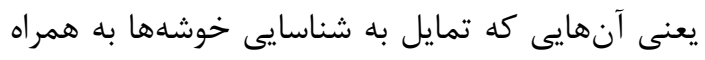

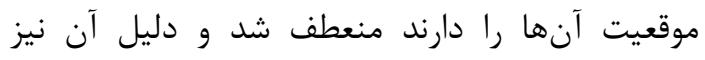
مىتواند جزئيات بيشتر و اطلاعات عملىترى باشد كه إند

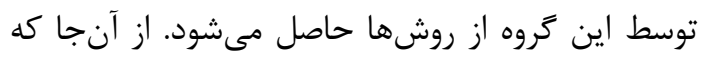

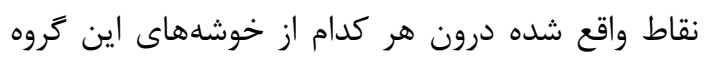

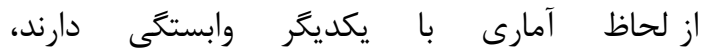

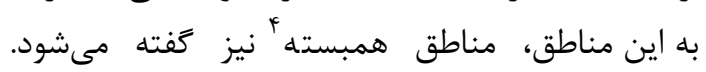

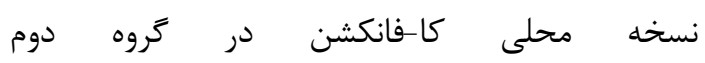
روشهاى خوشهبندى جاى مى ميرد.

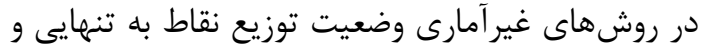
بدون در نظر كرفتن فرض صفر بررسى مىشود.

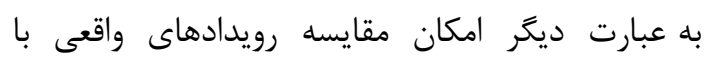
نمونههاى قابل انتظار وجود ندارد. اين امر باعث مىشود

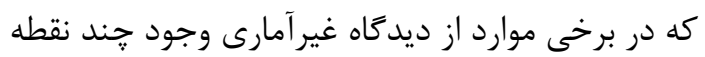

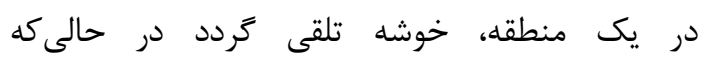

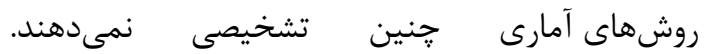

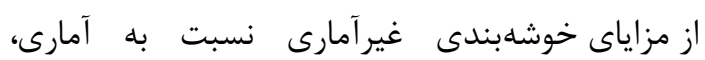

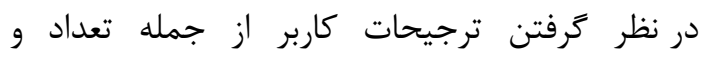
اندازه خوشهها است. روشهاى كا-مينز، كا-مدويدز هات و سلسله مراتبى نمونههاى خوشهبندى غيرآمارى هستند.

\section{r-1 - كا-فانكشن محلى شبكه مبناء} نسخه محلى كا-فانكشن روى شبكه توسط يامادالو و

${ }^{1} \mathrm{~K}$-function

${ }^{2}$ O'Driscoll

${ }^{3}$ Okabe

${ }^{4}$ Correlated

${ }^{5} \mathrm{~K}$-medoids

${ }^{6}$ Local network $K$-function 
آن است كه خوشهها، تكههاى به هم متصل شبكه را

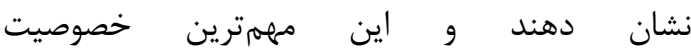

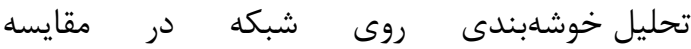
با نمونه معمول آن در صفحه است. براى تضمين وجود

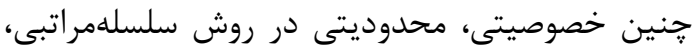

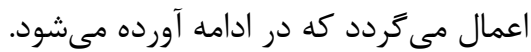

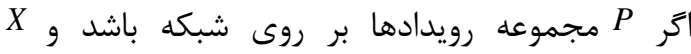

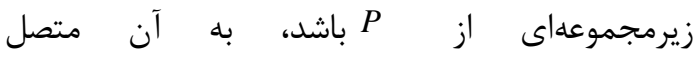

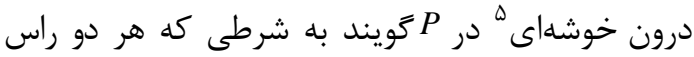
در X از طريق مسيرى در T به يكديخر متصل شوند

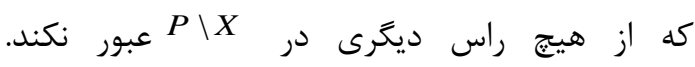

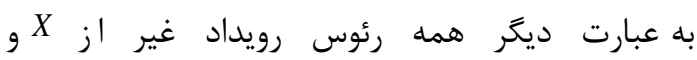
اتصالات آنها در T رات حذف كرده و متصل بودن در بقيه شبكه تعريف مىشود. بلعنوان مثال شبكه شكل r را در نظر بكيريد كه دواير توير، رئوس رويداد

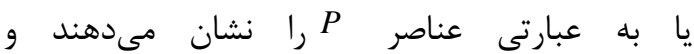
دواير توخالى، رئوس غير رويدادى را نشان مىدهند.

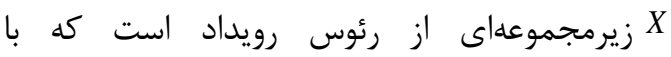
منحنى بسته خط קֶين در اطراف آن مشخص شدهاست. دو راس در X از طريق مسير يكه عبورى از راس مركزى به هم متصل شدهاند.

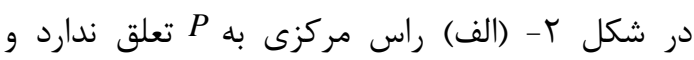

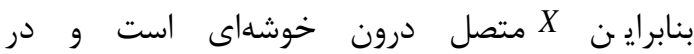
شكل Y-(ب) راس مركزى متعلق به P است و بنابراين

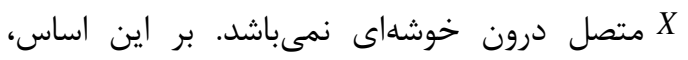

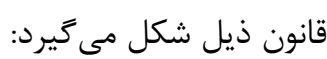

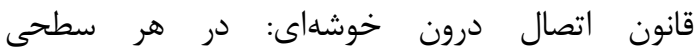
از خوشهبندى، دو خوشه با هم تركيب شوند كه X در باشد

\footnotetext{
${ }^{5}$ Intra-cluster connected
}

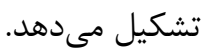

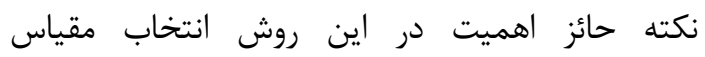

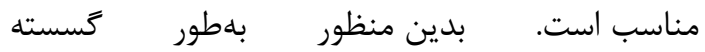

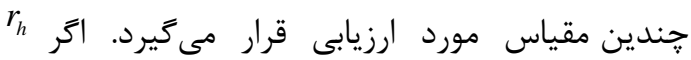
مقياس خوشهبندى در نظر كرفته شود و

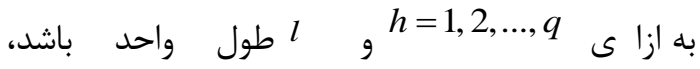
منطقه مورد مطالعه با استفاده از كا-فانكشن سراسرى و والور

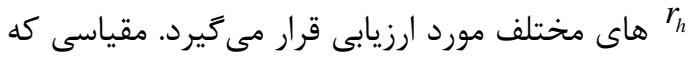

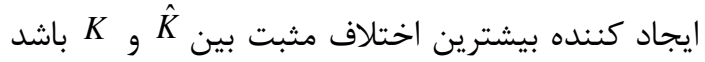
بهنوان مقياس مناسب انتخاب مى خردد. r-r- خوشهبندى سلسلهمراتبى'

روش سلسـهمراتبـى را مسىتـوان از طريـق يـك مثــال

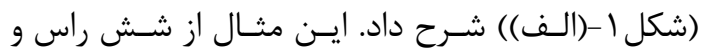

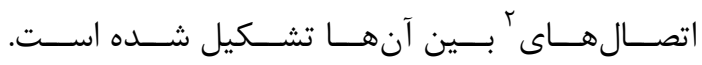

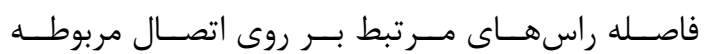

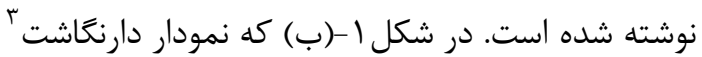

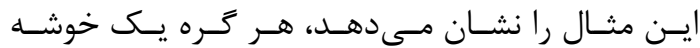
تكعضوى را مشخص مى كند كه خوشههاى سطح صفر هـر هستند. فاصله بـين بنابراين با يكديخر تركيب شده و

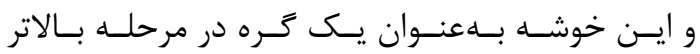

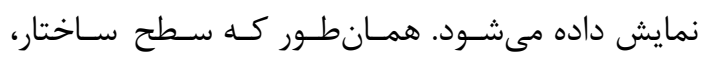

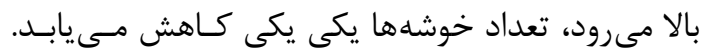

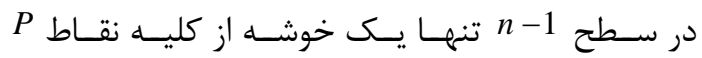

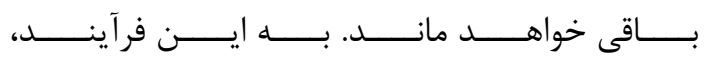

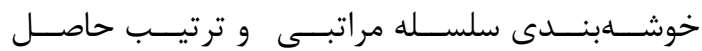

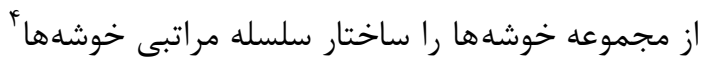
كويند. از آنجا كه با ساختار شبكه كار مىشود، انتظار طبيعى

${ }^{1}$ Hierarchical clustering

${ }^{2}$ Edge

${ }^{3}$ Dendogram

${ }^{4}$ Hierarchical structure of the clusters 


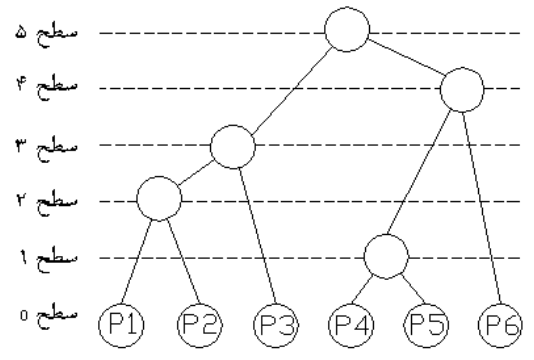

$(ب)$

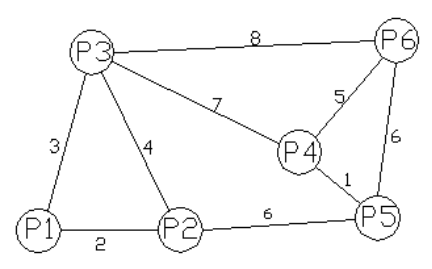

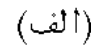

شكل ا-(الف) تراف متشكل از شش راس رويداد (ب) نمودار دارنكاشت تراف

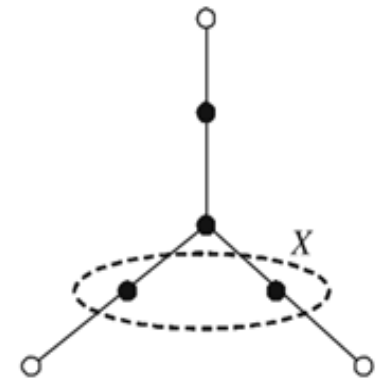

(ب)

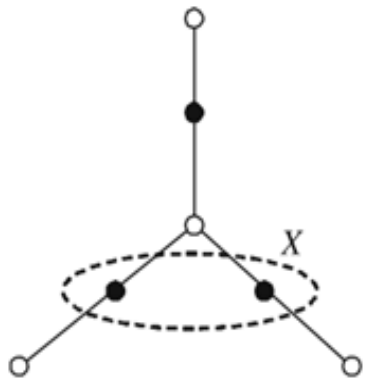

(الف)

شكل r-(الف) يك زيرمجموعه متصل درون خوشهاى (ب) زيرمجموعه غيرمتصل [rr]

كه نقطه m روى آن قرار كَفته بررسى مىشود. آر نقطه ديكرى روى اين اتصال، حداكثر به فاصله

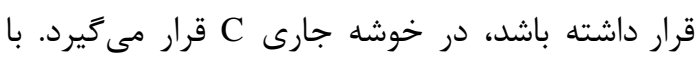

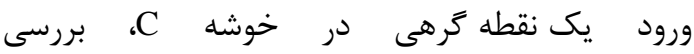

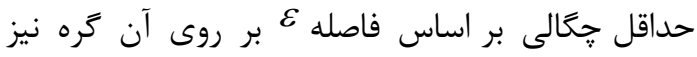

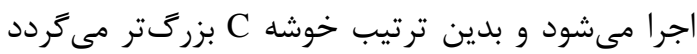

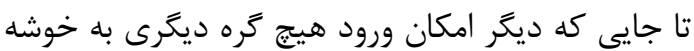

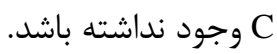

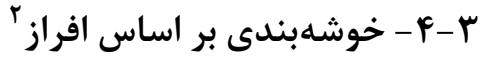

روشهاى افراز، نقاط را به $k$ ر كروه مختلف

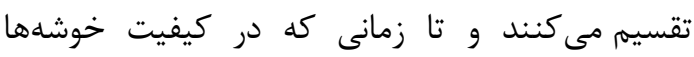
بهبودى حاصل نشود، به صورت تكراني نكارى اين نقاط

${ }^{2}$ Partitioning

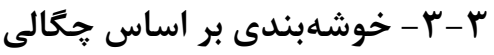

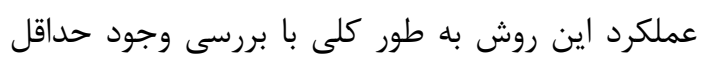

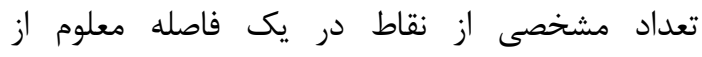

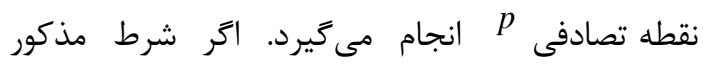

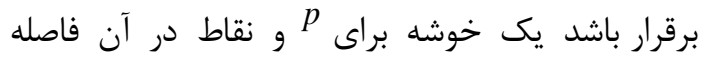

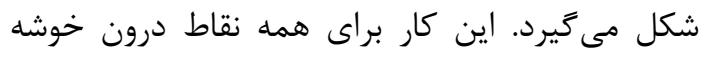

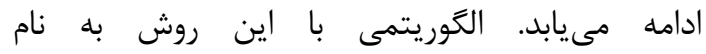

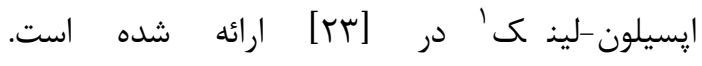

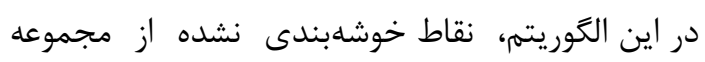
نقاط موجود، انتخاب شده و سنجش وجود إناط حداقل

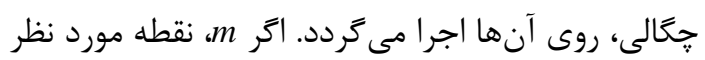

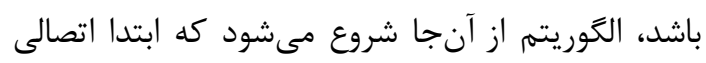

${ }^{1} \varepsilon-\operatorname{Link}$ 
را تجربه مىكند. اهميت شناخت مقياسهاى زمانى

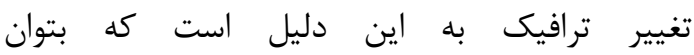

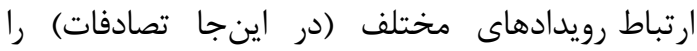
جهت برنامهريزى و تخصيص منابع تشخيص داد. تغييرات ترافيكى به صورت دقيقهاى، ساعتى، روزانه،

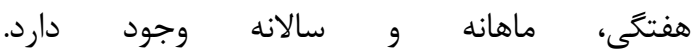
شيوه استخراج تصادفات وابسته در اين تحقيق با ذكر

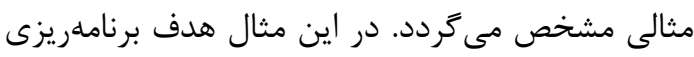

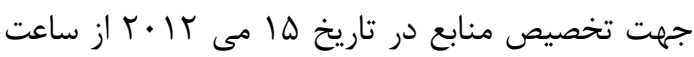

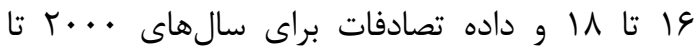

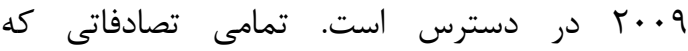

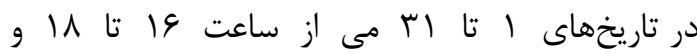

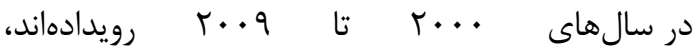
استخراج مى گردد. لازم به ذكر است از آنجا كه اين روز يك روز كارى محسوب مئشوده، تنها روزهاى كارى اين بازه در تحليل شركت مى مكنند و

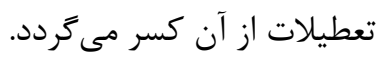

بعد از استخراج رويدادهاى وابسته زمانى نوردي نوديت

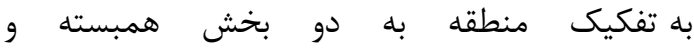
ناهمبسته مىرسد. اين كار بدين دليل انجام مى كيرد كه براى هر كدام از مناطق، يارامترهاى مجزايى

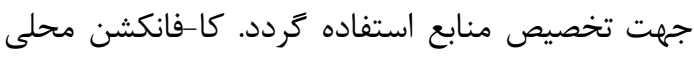
كه در قسمت انواع روشهاى خوشهبندى به آن آن إناعن

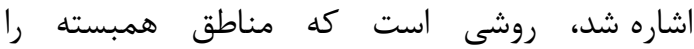

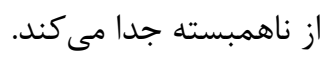
در ادامه لازم است كه كوجكسازى مناطق همبسته و ناهمبسته تا رسيدن به اندازه مشخص انجام كيرد. كوجكسازى مناطق به منظور تخصيص بهينه منابع

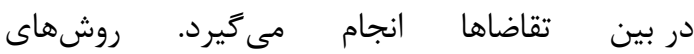
غيرآمارى خوشهبندى بر خلاف روشهاى آمارى، داراى

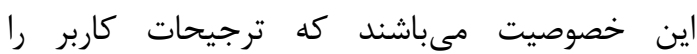

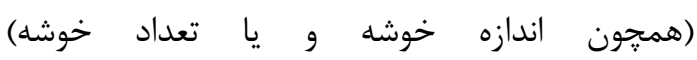
در نظر مى گيرند. از ميان سه روش سلسله مراتبى، افراز

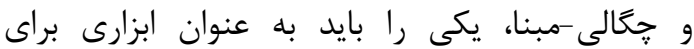

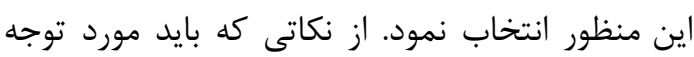

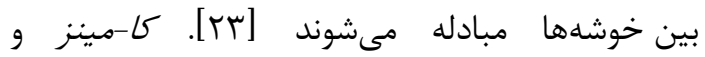
كا-مدويلز روشهاى موجود در اين طبقه هستند.

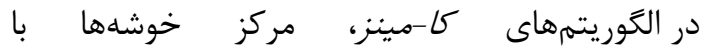
يك نقطه متوسط، مثل مركز ثقل نمايش داده مىشود

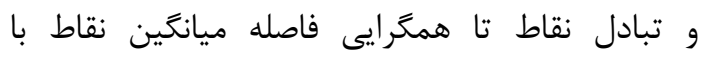
مقدار متوسط ادامه مىيابد. در الكَوريتمهاى كا-مدويدز

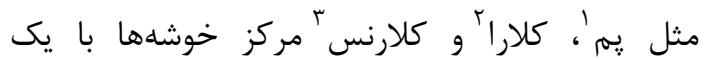
نقطه حقيقى از بين نقاط موجود نشان داده مىشوند. به اين نقطه حقيقى كه جايكزين نقطه ميانگين مى گردد، مدويدز گفته مىشود. ابتدا k تا نقطه بلهورت تصادفى به عنوان مدويدز انتخاب مىشود و ماند جمع فاصله نقاط تا نزديكترين مدويدز بلهعنوان

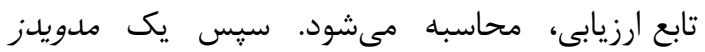
بانقطه تصادفى ديكر جايكزين مىشود. اتر مقدار

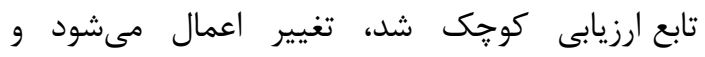

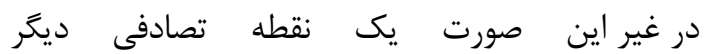
امتحان مى گردد. اين فرايند براى تعداد تكرار مشخصى

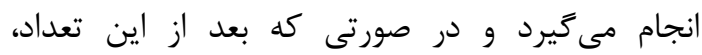
بهبودى در تابع ارزيابى حاصل نشد الكوريتم قطع شده

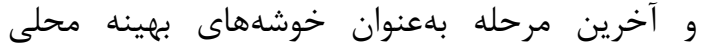
در نظر كرفته مىشود. اكر جه در اين روش كل نقاط در خوشهها جاى مى ديرند ولى تعيين يارامتر از محدوديتهاى آن مىباشد.

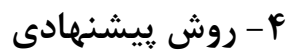
در گام اول روش بيشنهادى، لازم است كه در منطقه

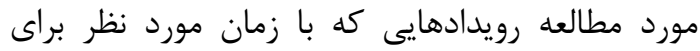
برنامهريزى وابستخى دارد، استخراج گرَدد. بهطور كلى يكى از شيوههاى در نظر ترفتن زمان در تحليلها،

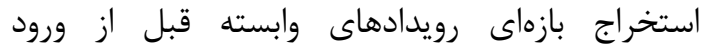
به تحليل مورد نظر است. شبكه معابر شهرى نيز در مقياسهاى مختلف زمانى تغييرات ترافيكى زيادى
${ }^{1} P A M$
${ }^{2}$ CLARA
${ }^{3}$ CLARANS 
$t_{d} \leq t_{s}$

$T \geq \frac{n}{Y \times d}\left(t_{d}+t_{p}\right):$

(†) رابطه (4)

(ه) رابطه

$n=\max \{x \mid x \in N\} \quad(N=$ Natural numbers $)$

در فرملهاى ب

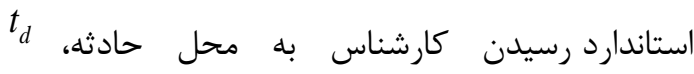

زمان واقعى رسيدن كارشناس به محل حادثه و وران

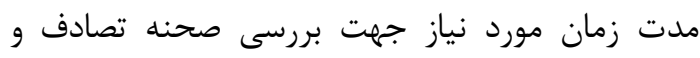

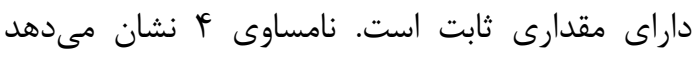
كه زمان واقعى رسيدن كارشناس به محل مابت حادثه

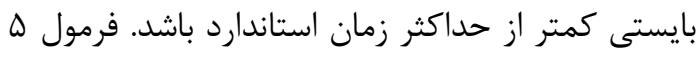

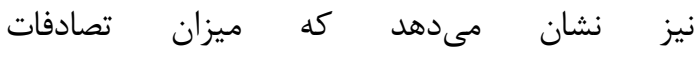
تخصيص داده شده به هر كارشناس تصادفات نبايد از توان كارشناس بيشتر باشد. هر دو طرف نامساوىهاى

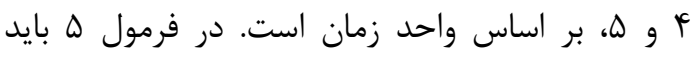

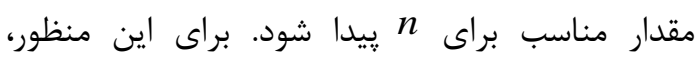

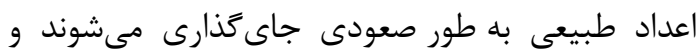

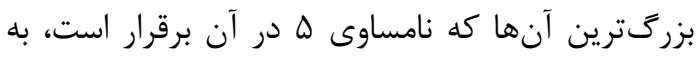

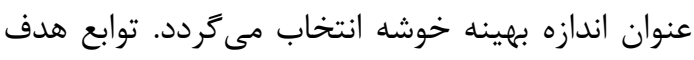
براى هر دو منطقه همبسته و ناهمبسته بهكار كرفته

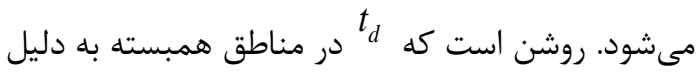

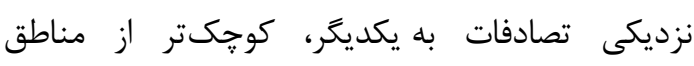

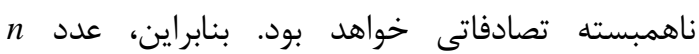
بزر كترى در مناطق همبسته به دست مئه آيد.

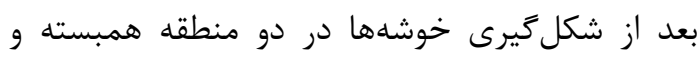

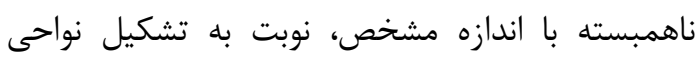

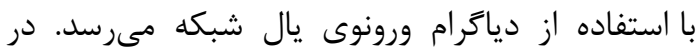

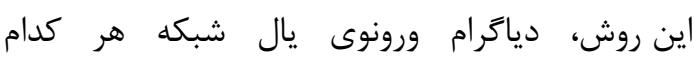

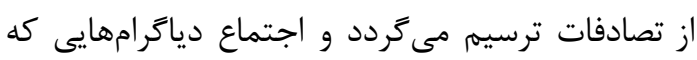
نقاط مركزى آنها (تصادفات) در يك خوشه قرار دارد دارد،

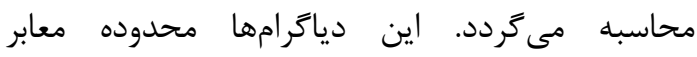
تحت يوشش هر كارشناس تصادف را تعيين مىنمايد.

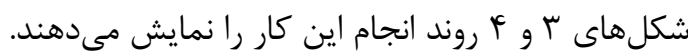

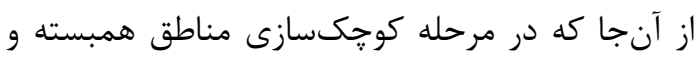

قرار كيرد آن است كه در تخصيص منابعى همجيون

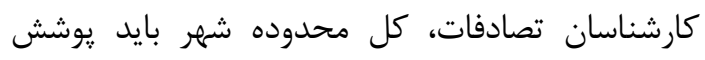
داده شود. يعنى روش به كار ترفته شده نبايد

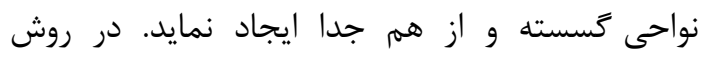

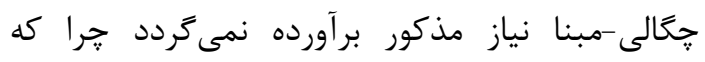

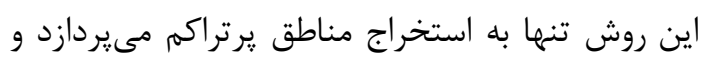

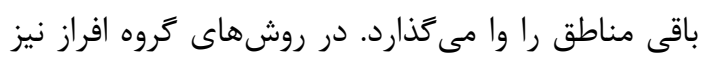

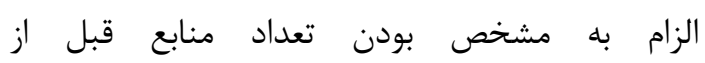

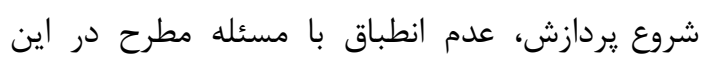

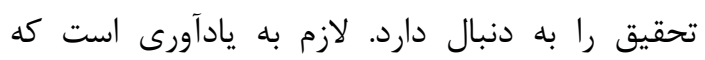

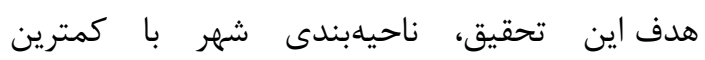

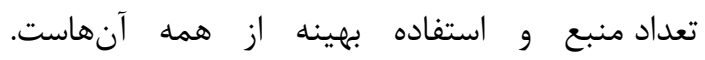
تنها روشى كه با اين رويكرد منطبق خواهد بود، روش سلسلهمراتبى است. اما مههمترين تصميم در استفاده از روش سلسلهمراتبى،

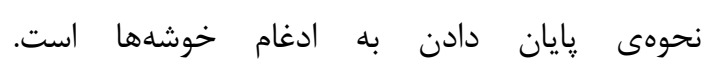

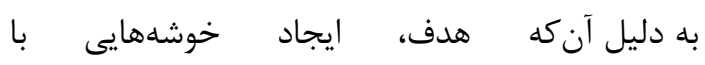

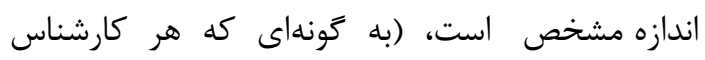

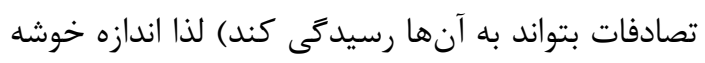
يعنى تعداد نقاطى كه در يك خوشه جاى مئى ركيرند،

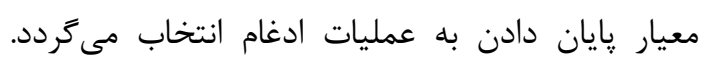

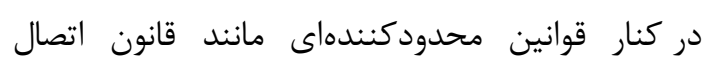
درون خوشهاى، تعداد رويدادهاى واقعى معمولا مضربى محدي

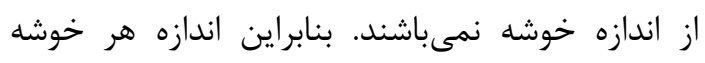

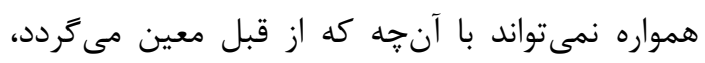

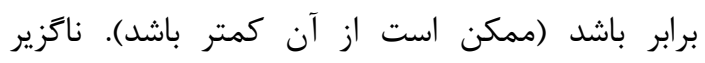

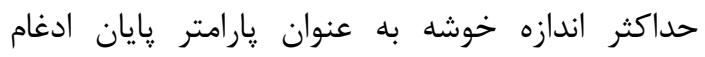
درنظر كرفته مى شود.

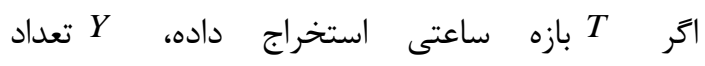

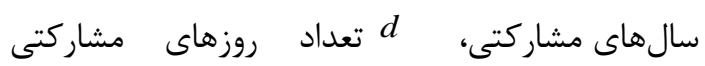

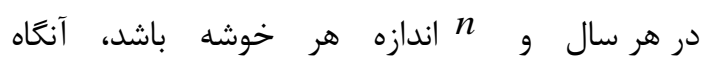
فرمولهاى أ و ه به عنوان توابع هدف ارائه مى بىردد: 
در .كل منطقه به گَونهاى كه قبلا شرح داده شد،

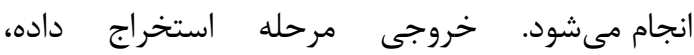

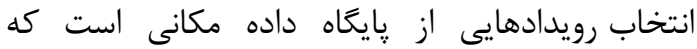
در بازههاى انتخابى توسط كاربر جاى كرفتهاند.

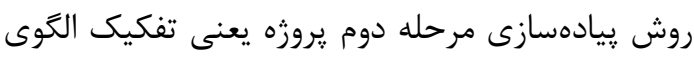

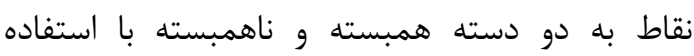

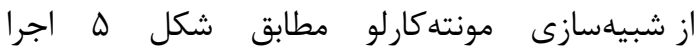
كشته است. اين مدل فرآيند با ايجاد m نقطه مرجع كه

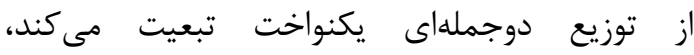
شروع مىشود. بهمنظور انجام اين ارزيابى، لازم است كه

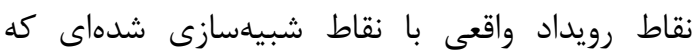

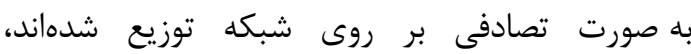

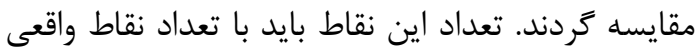

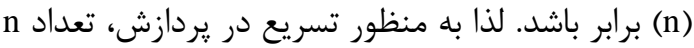
نقطه از m نقطه مرجع توليد شده بهطور تكرارى (تعداد

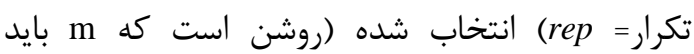

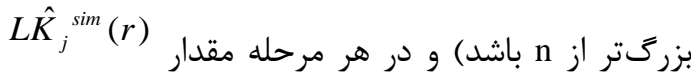
براى همه نقاط مرجع، محاسبه و ذخيره مى مردرد.

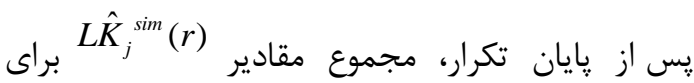
همه نقاط مرجع در هر مرحله محاسبه شده و بلهصورت

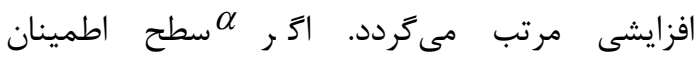
در نظر ترفته شده توسط كاربر باشد، آنغاه

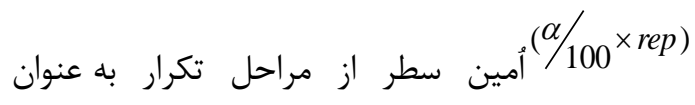
نماينده مقادير نقاط شبيهسازى شده انتخاب مى كردد. از سوى ديخر با محاسبه تابع

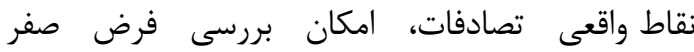

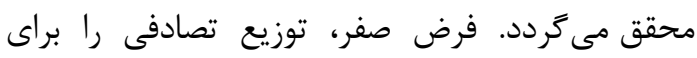
نقاط رويداد واقعى در نظر معى ميرد. در صورتى كه مقدار مركز خوشه تلقى مى گردد و فرض صفر رد مىشود.

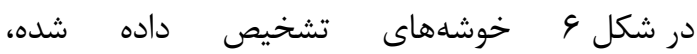
الكوى همبسته نقاط را نشان مىدهند و باقى مناطق تداى حكم مناطق ناهمبسته را خواهند داشت.
ناهمبسته از روش سلسلهمراتبى استفاده گرديده و

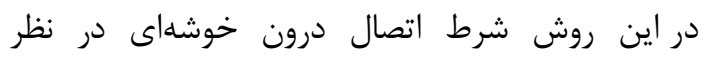

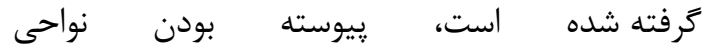
تضمين خواهدشد. از سوى ديكر استفاده از دياكرام ورونوى باعث اطمينان از يوشش كامل دئل منطقه خواهدبود. جرا كه دياكرام ورونوى تا رسيدن به به مرز

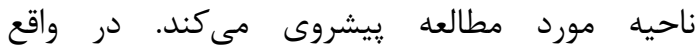
در تخصيص منابع، مقاومت ظاهرى در نظر كرفته نشده و تنها عامل قطع يال ورونوى، رسيدن به مرز ناحيه

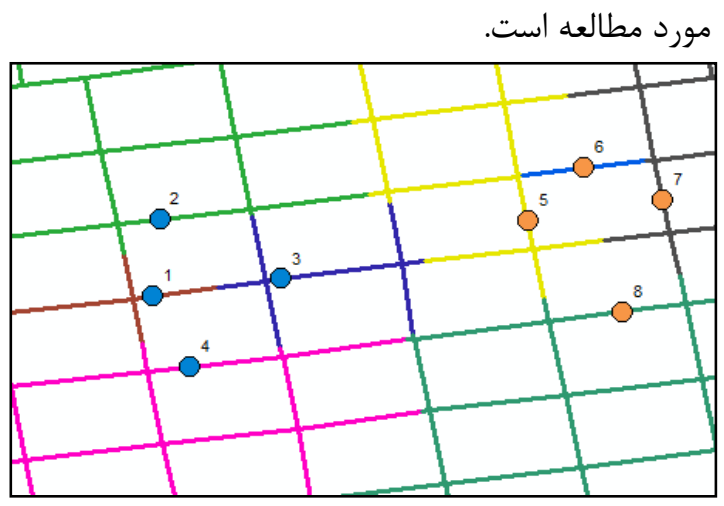

شكل ץ- - ترسيم دياكرام ورونوى يال شبكه براى 1 نقطه كه

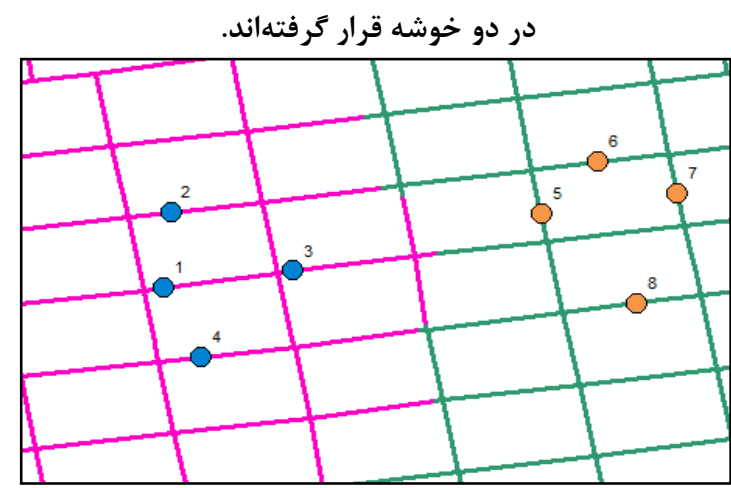

شكل F - اجتماع دياتر امهاى ورونوى يال شبكه مربوط به

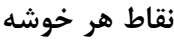

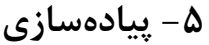

استخراج داده با استفاده از كلاسهاى يرسوجوى توصيفى' به زبان SQL انجام مى كَيرد. اين استخراج

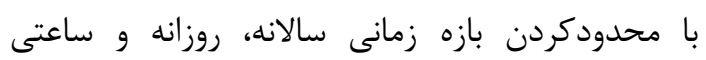

${ }^{1}$ Attribute Query

${ }^{2}$ Structured Query Language 
روشى نوين در تخصيص منابع متحرك بر روى شبكه...

محسن كودرزى و ديكر همكاران

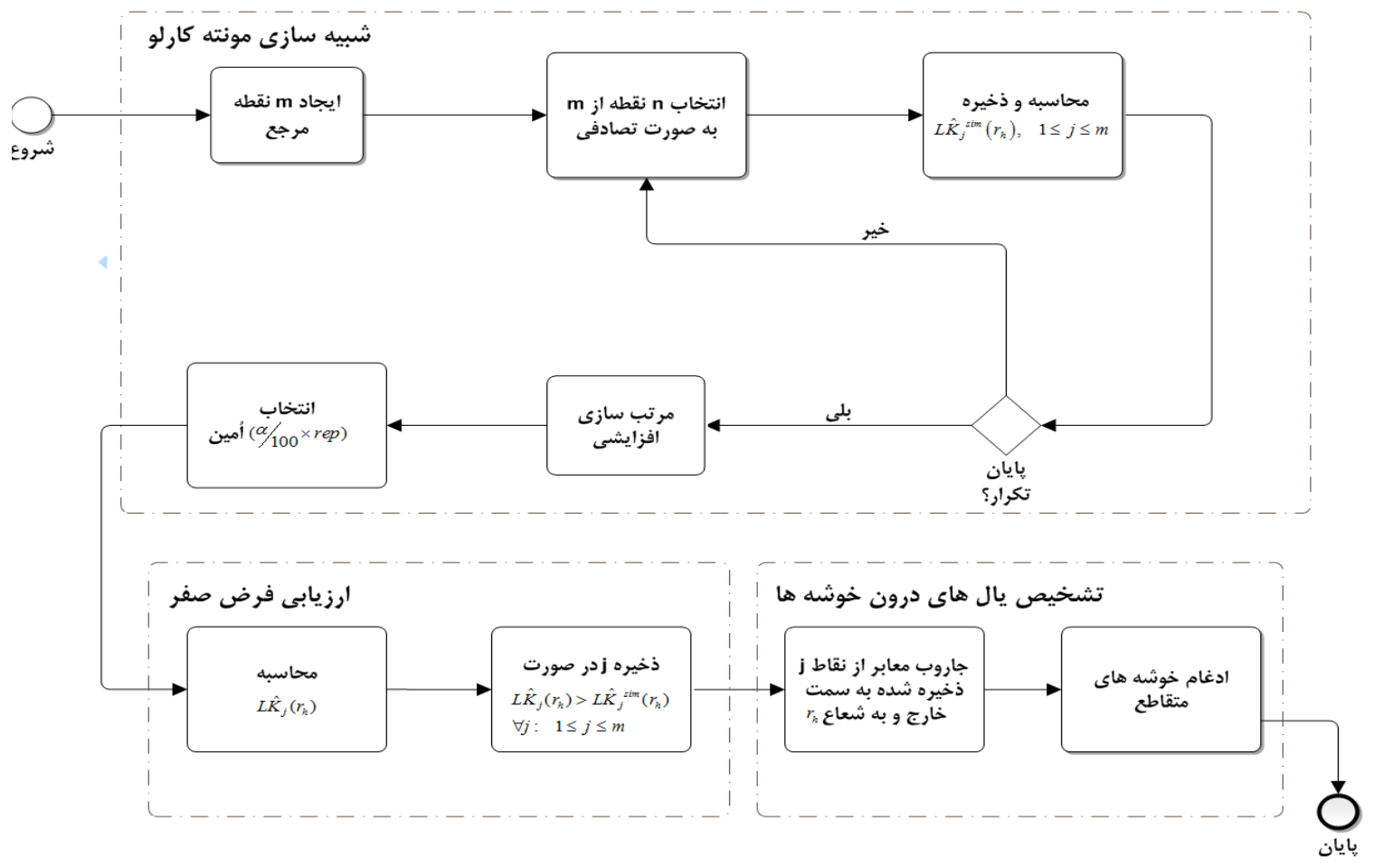

شكله - دياكرام شبيهسازى مونته كارلو در مرحله دوم روش بيشنهادى

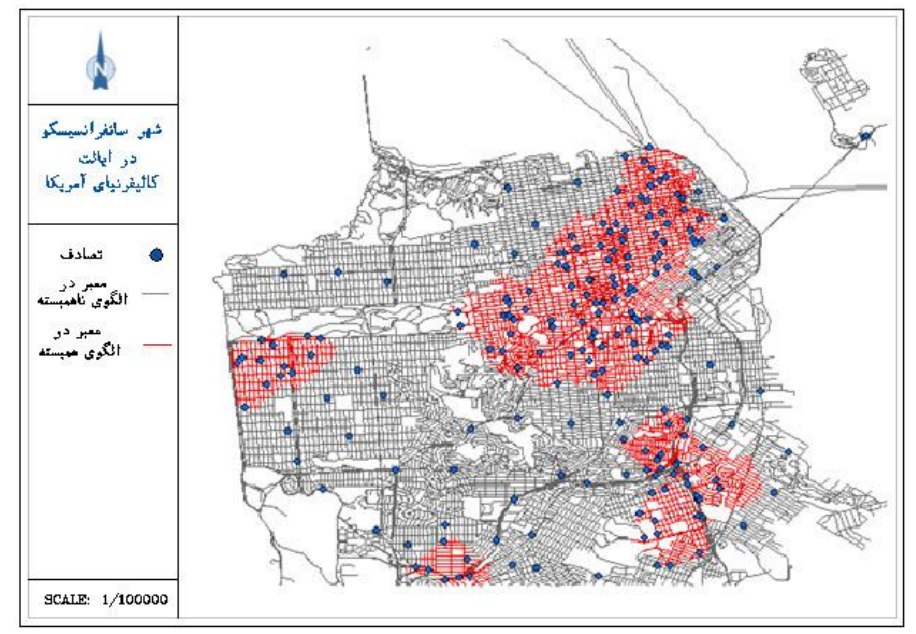

شكل 9- خروجى مرحله تفكيك الكوى نقاط

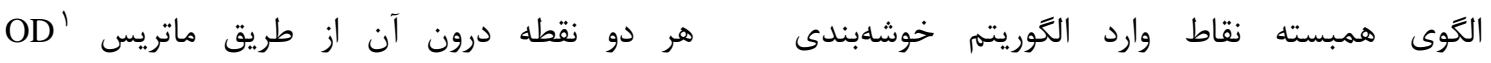

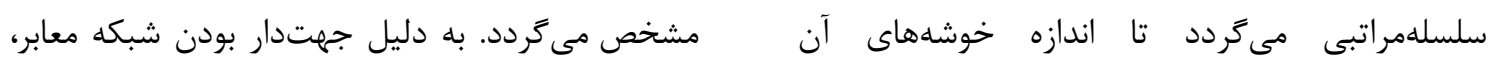

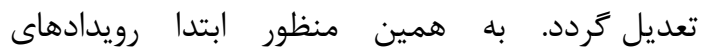
هر خوشه باصورت مجزا در نظر كرفته مىشود و فاصله 
ورونوى يال شبكه را نشان مىدهد.

\section{Districts Generation}

Input: Point-Clusters

Output: Link-Clusters

1. For every Point-Clusters do

2. $\mathrm{P} \leftarrow$ take out points within Link-Clusters

3. VD $\leftarrow$ Calculate Link Voronoi Diagram of $P$

Link-Cluster $\leftarrow$ Union VD

اشكال V و 1 و به ترتيب خوشههاى كوجك شده در ناحيه همبسته و ناهمبسته را نشان مى بهدد.

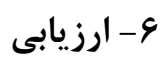

ميزان كارايى روش پيشنهادى، با مطالعه موردى

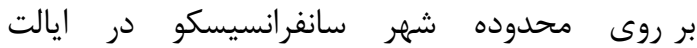
كاليفرنياى آمريكا سنجيده شده است. علت انتخاب اين منطقه، در دسترس بودن داده تصادفات شهرى آن آن

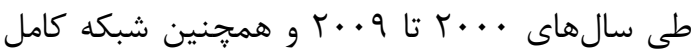

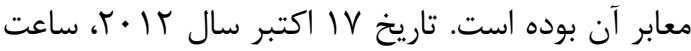

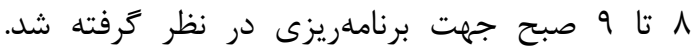

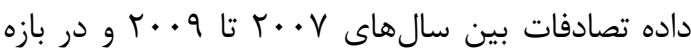
دو هفته قبل و بعد از تاريخ مذكور در ساعت 1 تا 9

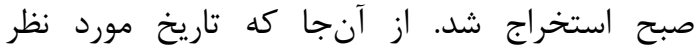

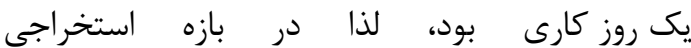
روزهاى تعطيل حذف گرديد. بنابراين · ا روز قبل و بعد از آن تاريخ در طى سه سال در نظر گرفته شد (جمعا • (9 روز كارى).

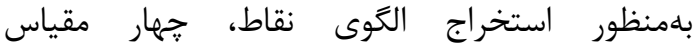
در نظر گرفته شد و مقادير كا-فانكشن سراسرى براى

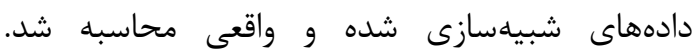

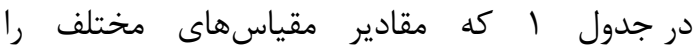
نشان مىدهد، مقياس • • له داراى بيشترين اختلاف بين مقياس مناسب انتخاب گرديد.

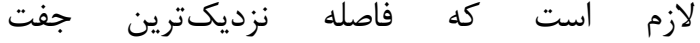
در دو خوشه مختلف در مسيرهاى رفت و ر برگشت محاسبه شده و ميانگين آنها مورد استفاده قرار گيرد. فاصله ميانخين رفت و برگشت نقاط به همراه شماره

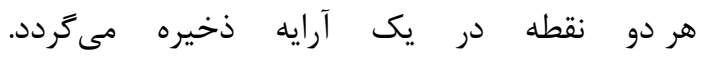

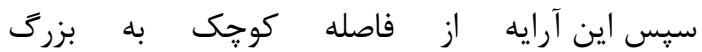

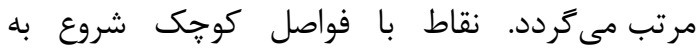
تركيب مى كنند و به هر كدام از آنها، نام خوشه جديد اختصاص داده مىشود. دو شرط بيشينهى اندازه خوشه و اتصال درون خوشهاى جهت تركيب دو خوشه در نظر گرفته شده است. اين كار تا جايى ييش مىرود كه ديخر امكان تركيب هيج دو خوشهاى با هم

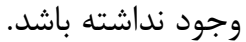
اما قسمت خارج از محدوده همبسته نقاط نيز بهصورت

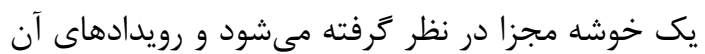

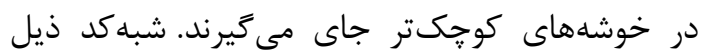

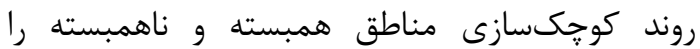
نشان مى ندهد.

\section{Cluster Shrinking}

Input: Accidents, Link-Clusters, ClusterSize Output: Point-Clusters

1. For every Link-Clusters do

2. Col $\leftarrow$ Take out intersected Accidents with Link-Clusters

3. OD $\leftarrow$ Create Origin-Distance matrix

4. Dist[1] $\leftarrow$ Number of origin points

5. Dist[2] $\leftarrow$ Number of Destination points

6. Dist [3] $\leftarrow$ Calculate average distance from OD

7. Sort Dist incrementally based on Dist[3]

8. For every rows in Dist

$\mathrm{C} \leftarrow$ Cluster(Dist[1]) $\quad 9$.

$\mathrm{C}^{\prime} \leftarrow$ Cluster(Dist[2]) 10

$\mathrm{L} \leftarrow$ ClusterSize $(\mathrm{C})+$ ClusterSize $\left(\mathrm{C}^{\prime}\right) \quad 11$.

If $\mathrm{L}<=$ ClusterSize and merge $\left(\mathrm{C}, \mathrm{C}^{\prime}\right)$ is intra- cluster connected then

Merge (C, C') 13.

شبهكد ذيل نحوه ناحيهبندى با استفاده از دياگرام 


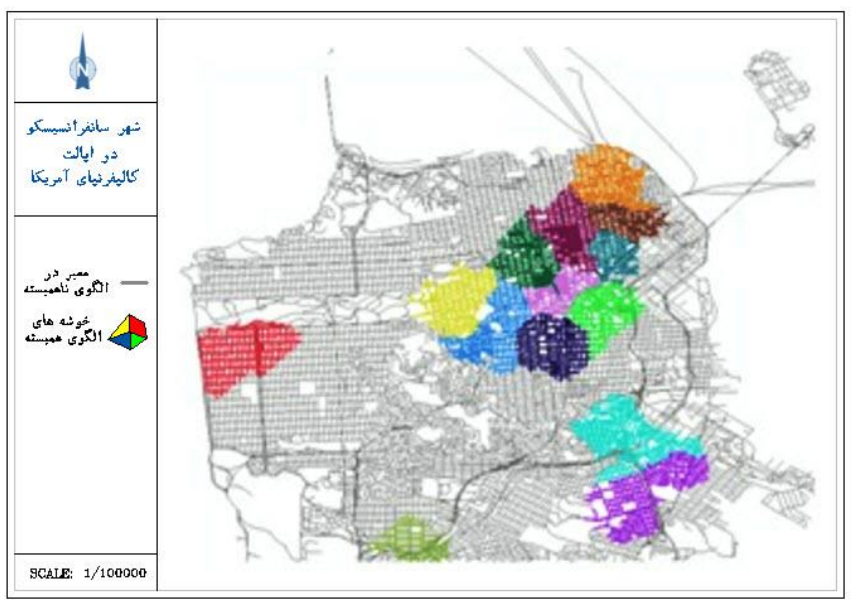

شكل V- تعيين محدودههاى كوجگ شده در ناحيه همبسته

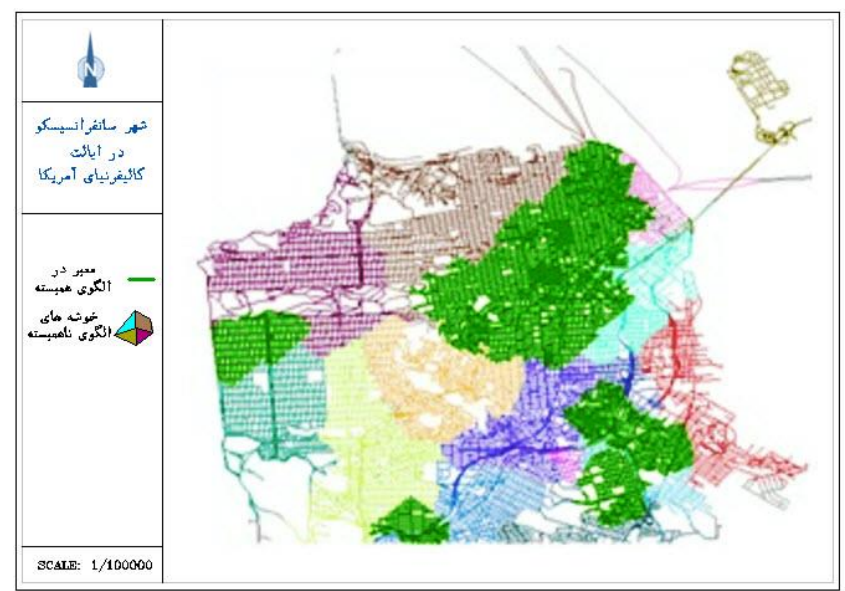

شكل ^- تعيين محدودههاى كوجى شده در ناحيه ناهمبسته

اندازهاى است كه اولا حداكثر استفاده از منبع

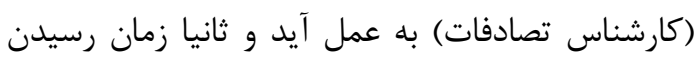

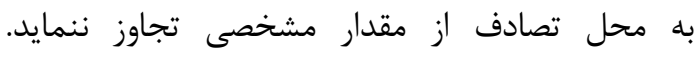

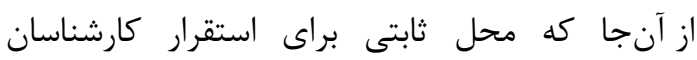

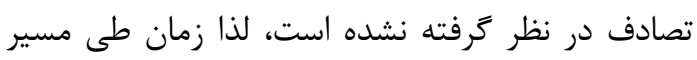
تا محل تصادف به صورت كسرى از زمان كلى عبور

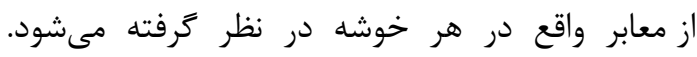

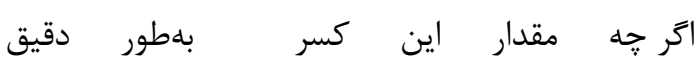

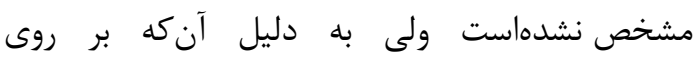

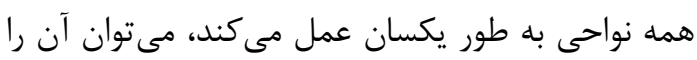

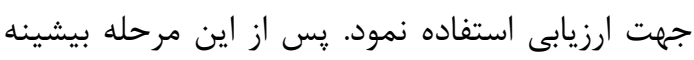

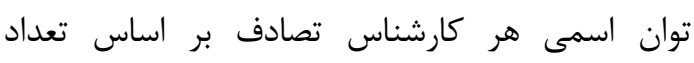
تصادف در هر ناحيه مشخص مى مركردد. اين كار
جدول ا- انتخاب مقياس مناسب جهت ارزيابى

\begin{tabular}{|c|c|c|c|c|}
\hline$\hat{K}-\hat{K}^{s i m}$ & $\hat{K}$ & $\hat{K}^{\text {sim }}$ & مقياس (متر) & $\#$ \\
\hline$+r / \Lambda 9$ & $1919 / 4 F$ & $1918 / \pi \Delta$ & $1 \ldots$ & 1 \\
\hline$+r / 91$ & $r \cdot \mid r / \cdot q$ & $r \cdot 1 \cdot / 1 \Lambda$ & $1 r \Delta$. & \\
\hline$+\varphi / \cdot 1$ & $r \cdot 1 N / 99$ & $r \cdot \mid r / q \Lambda$ & $10 \cdots$ & r \\
\hline$+r(\lambda)$ & $r \cdot r \Lambda / T V$ & $r \cdot r \Delta / \Delta Q$ & $I V \Delta$. & \\
\hline
\end{tabular}

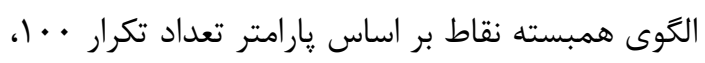

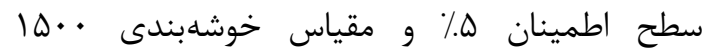

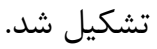

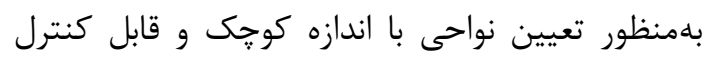
توسط هر كارشناس تصادفات، لازم است كه منطقه ندازه

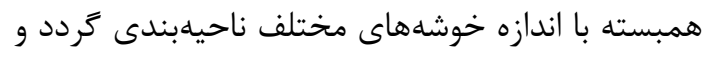
بهترين اندازه خوشه انتخاب شود. بهترين اندازه خوشه، 
زمان رسيدن به محل تصادف از $t^{\prime}$ تجاوز ننمايد.

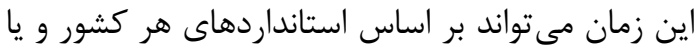

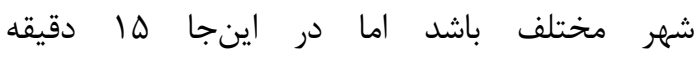
در نظر گرفته شده است. مقادير انتخابى از هر جدول با ماندا رنَ متمايز مشخص شدهاند.
با استفاده از فرمول ه انجام مى كيرد.

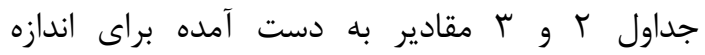
خوشههاى مختلف را در مناطق همبسته و ناهمبسته نشان مى ندهد. اندازه خوشه مناسب در اين جداول، اندازماى است كه

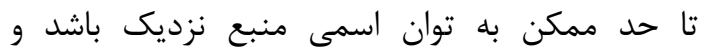

جدول r - انتخاب اندازه خوشه مناسب جهت منطقه همبسته

\begin{tabular}{|c|c|c|c|c|c|}
\hline خوشه & 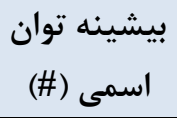 & 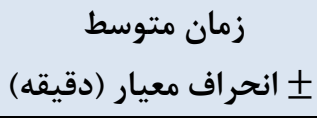 & 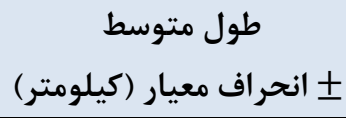 & خوشه & \# \\
\hline rq & $1 \cdot r / 4$ & $Y / A T \pm \cdot / 9 \varphi$ & $r \cdot|\Lambda| \pm \varepsilon / 4 \lambda$ & $r$. & 1 \\
\hline rG & $1 \cdot T / F T$ & $\Delta / 1 \Delta \pm 1 / \cdot \Delta$ & $r r / r \Lambda \pm \varepsilon / q r$ & $r \Delta$ & r \\
\hline سץ & $1 \cdot 1 / 0$ & $\Delta / F \varphi \pm 1 / / F$ & $r G / F r \pm V / \Delta q$ & r. & r \\
\hline ו & $99 / 5$ & $\varphi / \pi \pm 1 / \mu \Lambda$ & r//VG $\pm 1 / 19$ & id & f \\
\hline r & $9 \Delta / /$ & $V / \Lambda \pm I / V I$ & $\Delta T / T \Delta \pm 11 / F r$ & $\Delta \cdot$ & $\Delta$ \\
\hline r) & $9 \% / 9$ & $\Lambda / \Lambda V \pm 1 / \Lambda r$ & $\Delta V / T r \pm|r /| \Lambda$ & $\Delta \Delta$ & 4 \\
\hline 11 & 9 . & $1 \cdot \pm T / 1$ & G9/VG $\pm \mid F / \cdot F$ & 4. & $\mathrm{V}$ \\
\hline 14 & $\Lambda F / 1$ & $I r / \Lambda \pm r / V r$ & $\Lambda \Delta / \Lambda r \pm I \Lambda / T V$ & 90 & $\wedge$ \\
\hline IT & $\Lambda$ & $1 \phi / \cdot r \pm r / r q$ & $1 \cdots / / r \pm r r / \Delta q$ & V. & 9 \\
\hline 1. & $V F / T$ & $\mid N / \Delta F \pm r / \Lambda F$ & $\| r \cdot / V \pm r \Delta / \Delta \varphi$ & $V \Delta$ & 1 . \\
\hline$\Lambda$ & $9 V / 9$ & $r r / T V \pm F / V I$ & $|\Delta \cdot / \tau| \pm \pi \mid / r \Delta$ & ᄉ. & 11 \\
\hline
\end{tabular}

جدول بـ- انتخاب اندازه خوشه مناسب جهت منطقه ناهمبسته

\begin{tabular}{|c|c|c|c|c|c|}
\hline خوشه & 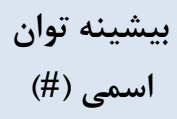 & 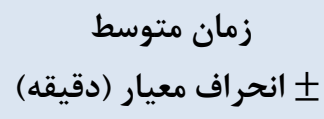 & 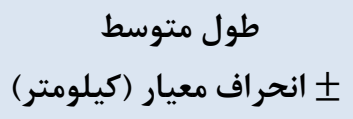 & خ اندازه & $\#$ \\
\hline 11 & $\Lambda 9 / 4 \wedge$ & $1 \cdot / r \pm 1 / 8 \Delta$ & $49 / \pi^{4} \pm 11 / \cdot 4$ & $r$. & 1 \\
\hline 9 & $\Lambda F / \Lambda F$ & $1 r / F r \pm 1 / 9 r$ & $1 / / 1 \pm 1 r / \Delta r$ & $r \Delta$ & r \\
\hline V & NT/VT & $\mid r / \Delta r \pm r / \Delta \Lambda$ & $1 \cdot F / r \Lambda \pm 19 / \Lambda$ & $r$. & r \\
\hline 9 & $V V / 9 \Delta$ & $18 / 11 \pm r / V \varepsilon$ & $|r| / 99 \pm 11 / 9$ & $r \Delta$ & f \\
\hline 9 & $V V / 9 D$ & $19 / 1 \Lambda \pm r / \cdot r$ & $|r| / \& \varphi \pm r \cdot / r \Delta$ & r. & $\Delta$ \\
\hline$\Delta$ & sV/rq & $r r / F r \pm r / \& q$ & $\mid F \varphi \pm T Y / \cdot G$ & $4 \Delta$ & 9 \\
\hline$\Delta$ & qV/Tq & $r r / F r \pm r / q q$ & $\mid F \varphi \pm T F / \cdot \varphi$ & $\Delta \cdot$ & v \\
\hline r & $\Delta q / \Delta F$ & $r \cdot / F q \pm F / \Delta F$ & $\mid \wedge r / \Delta \pm r \cdot / r$ & $\Delta \Delta$ & $\wedge$ \\
\hline r & $\Delta q / \Delta F^{F}$ & $r \cdot / r q \pm r / \Delta r$ & $1 \Lambda r / Q \pm r \cdot / r$ & 4. & 9 \\
\hline f & $\Delta q / \Delta F$ & $r \cdot / F q \pm F / \Delta F$ & $\mid \Lambda r / \Delta \pm r \cdot / r$ & 90 & 1 . \\
\hline r & FN/9V & $F / D \mid \pm 9 / T V$ & $r F T / r \pm r \cdot / \Delta r$ & $v \cdot$ & 11 \\
\hline
\end{tabular}


قرار گيرد. در حقيقت در روش جايكزين تفكيك منطقه

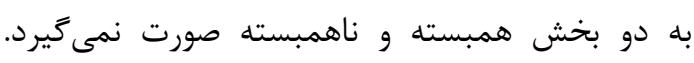

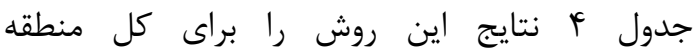

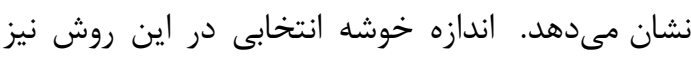
با رنت متمايز مشخص شده است.
جهت ارزيابى روش بيشنهادى لازم است كه نتايج آن

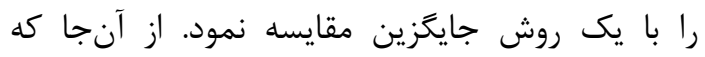

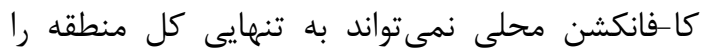

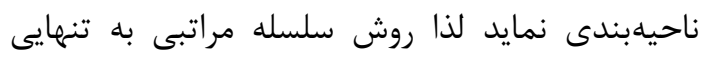

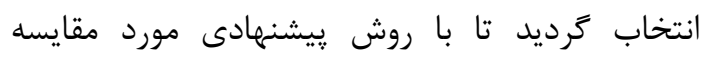

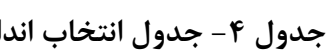

\begin{tabular}{|c|c|c|}
\hline 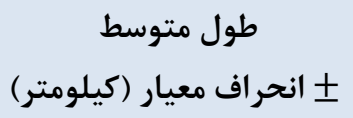 & خوشه & $\#$ \\
\hline$|c| / \cdot \Lambda \pm 1 \varepsilon / \Delta \varphi$ & TQ & 1 \\
\hline$F \Delta / 9 V \pm I N / 9$ & $r$. & r \\
\hline$\Delta r / \backslash \Lambda \pm r \cdot / \Lambda \Delta$ & ra & r \\
\hline$\Delta \wedge / \Delta I \pm T r / \varepsilon 1$ & r. & f \\
\hline$\varepsilon \varphi / \Delta \Lambda \pm r \varepsilon / \Lambda \Delta$ & Fa & $\Delta$ \\
\hline$V I / \Delta I \pm r N / \Delta r$ & $\Delta \cdot$ & 9 \\
\hline$\Lambda V / V \vee \pm r \Delta / \Delta \Lambda$ & $\Delta \Delta$ & V \\
\hline $1 \cdot 1 / \varepsilon r \pm r \cdot / \Lambda q$ & 4. & $\wedge$ \\
\hline$\| r / \Delta \Lambda \pm F \Delta / \Lambda \mid$ & $9 D$ & 9 \\
\hline$\| r / \Delta \Lambda \pm r \Delta / \Lambda 1$ & V. & 1 . \\
\hline$|r \cdot| q \Lambda \pm r \wedge / q$ & $V \Delta$ & 11 \\
\hline
\end{tabular}

در نواحى، بر اساس اندازههاى متفاوت خوشه از مقادير به دست آمده קنين نتيجه مىشود كه براى ديده مىشود. بر اساس اين نمودار، منطقه همبسته تاريخ مذكور به جاى استقرار كV كارشناس تصادف

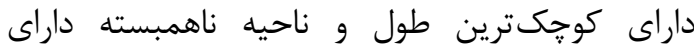

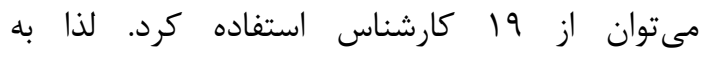
بيشترين طول خوشهاى هستند و اين امر نشان

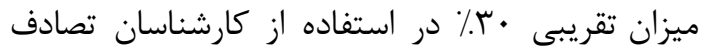
از صحيح بودن انديشه تفكيك منطقه به دو قسمت صرفهجويى به عمل آمده است. همبسته و ناهمبسته دارد.

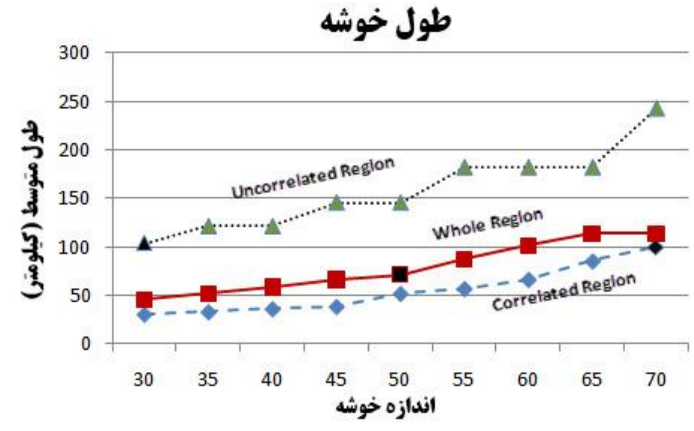

شكل 9 - نمودار طول متوسط معابر در خوشههاى حاصله با تغيير اندازه خوشه

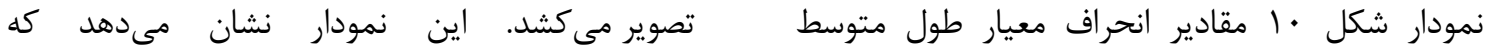
اجراى روش ييشنهادى مى تواند تاثير بهسزايى در ايجاد 


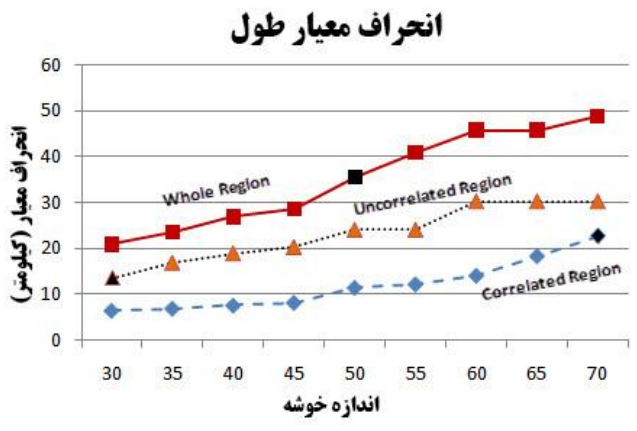

شكل •1-نمودار انحراف معيار طول معابر خوشهها بر اساس اندازه خوشه

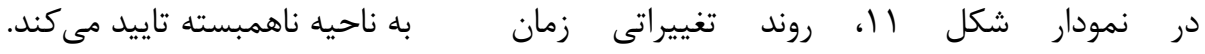

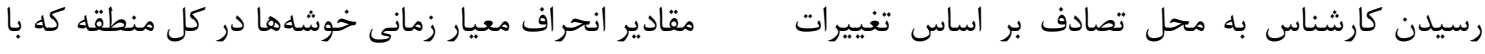

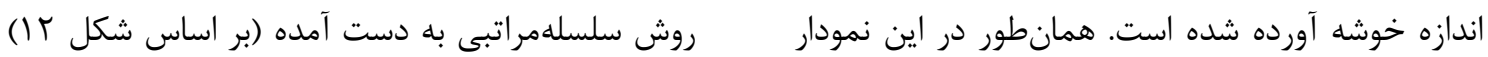

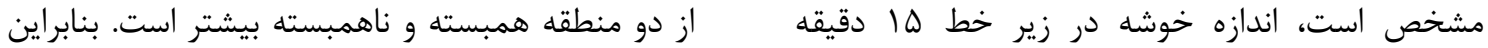

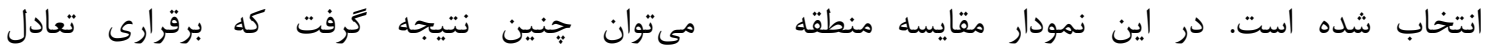

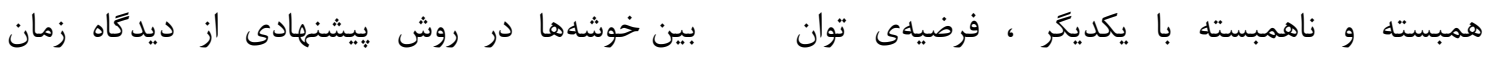

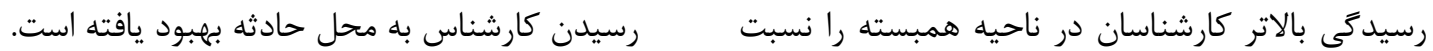
زمان رسيدن

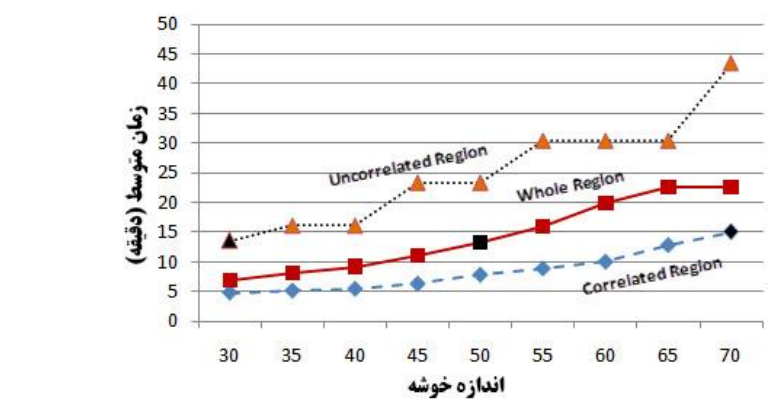

شكل Iل - نمودار زمان رسيدن كارشناس به محل حادثه با تغيير اندازه خوشه

انحر اف معيار زمان به مان

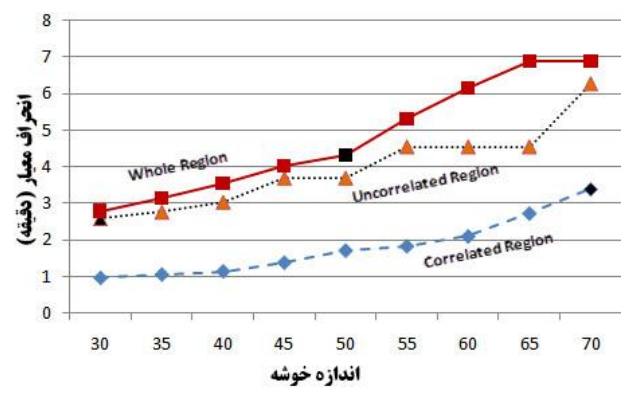

شكل rا - نمودار انحراف معيار زمان رسيدن به محل حادثه بر اساس اندازه خوشه

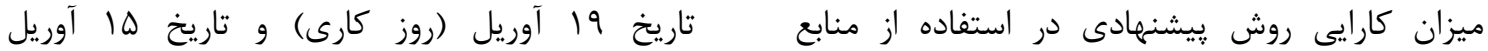

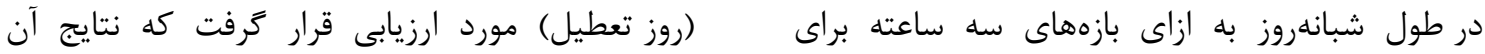


در برخى ساعات اثر معكوس دارد. تاثير معكوس روش

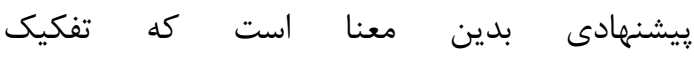
منطقه مورد مطالعه به دو قسمت همبسته و ناهمبسته،

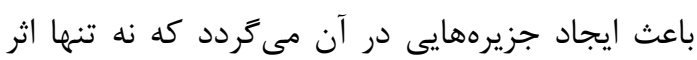

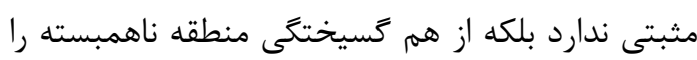

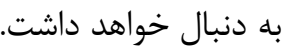

در نمودار شكل سا به تصوير كشيده شده است.

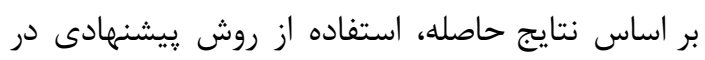

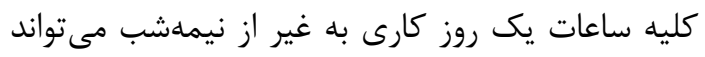
مفيد و موثر واقع گردد. بر اساس اين جدول، ميانكين

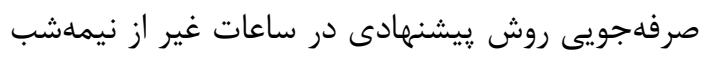

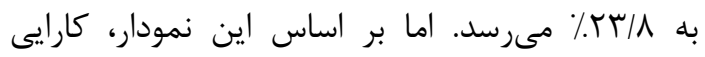

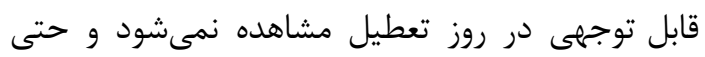

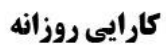

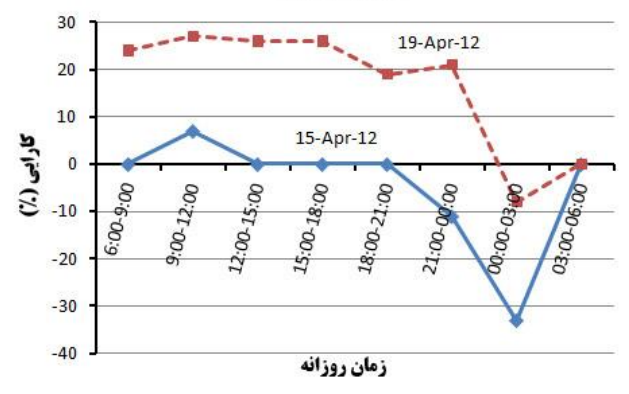

شكل rآ- ميزان كارايى روش بيشنهادى براى روز كارى و تعطيل

آز كارشناسان تصادفات و البته زمان استاندارد رسيدن آنها به محل حادثه انجام كرفت. در نهايت خوشههاى

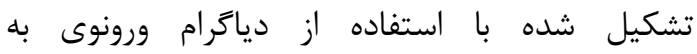
شبكه معابر تعميم داده شد و محدوده تحت كنترل هر كدام از كارشناسان تصادف مشخص كرديد.

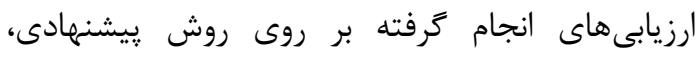

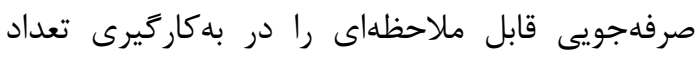

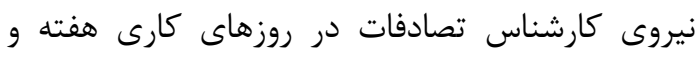

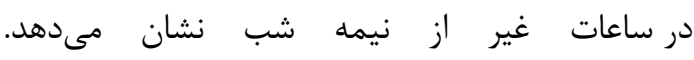

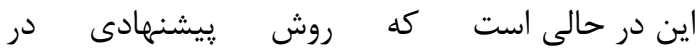
روزهاى تعطيل و ساعات نيمه شب كار ايى مورد انتظار و قابل توجهى را از خود بروز نداده است.

\section{^- تحقيقات آتى}

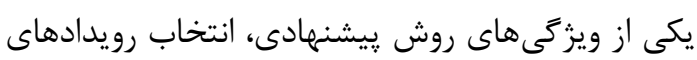

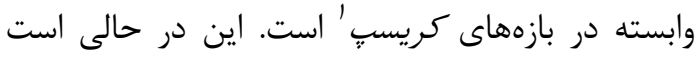

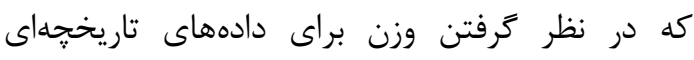
تصادفات باعث نزديكتر شدن خرفن خروجى مورد نظر نادر نايخ

\footnotetext{
${ }^{1}$ Crisp
}

\section{V- - لمعبندى و نتيجه}

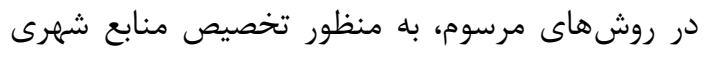

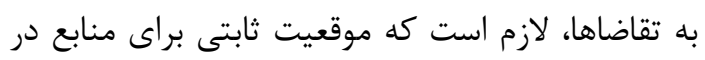

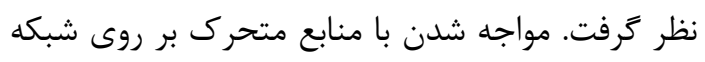

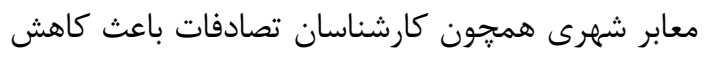

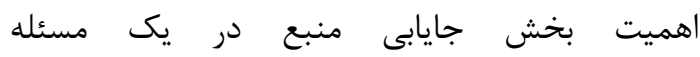

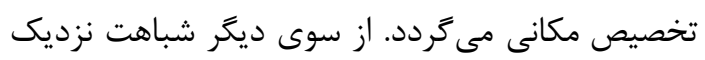
بين مفهوم خوشهبندى و تخصيص مكانى باعث ترديص درديد كه در اين تحقيق از خوشهبندى بلهعنوان ابزارى

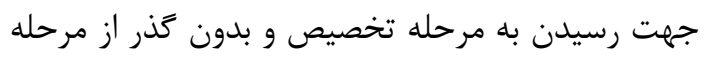

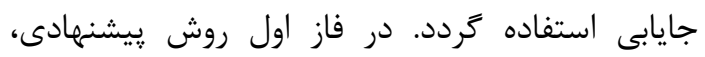

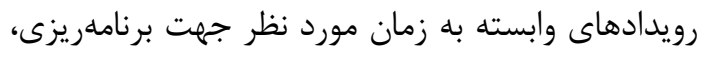

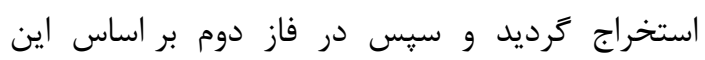

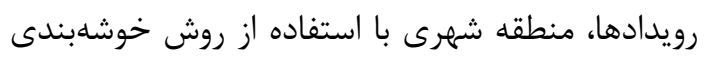
كا-فانكشن محلى به دو بخش همبسته و ور ناهمبسته

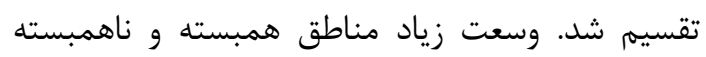

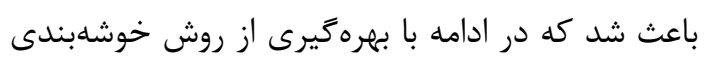
سلسلهمراتبى، به كوجكسازى اين مناطق اقدام كردد. فرآيند كوجكسازى با در نظر كرفتن توان هر كدام 


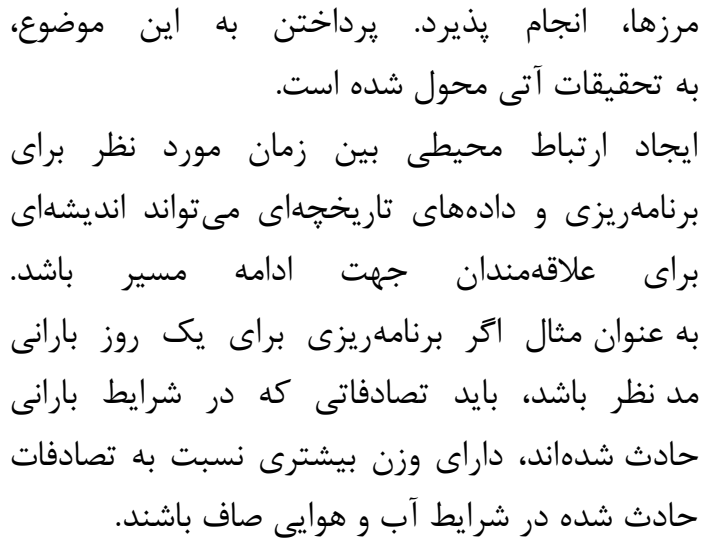

[1] S. Fotheringham and M. Wegener, Spatial Models and GIS: New and Potential Models vol. 7: CRC, 1999.

[2] F. Karimi, M. R. Delavar, and M. A. Mostafavi, "Space allocation of educational centers using multiplicatively weighted voronoi diagram," in ISPRS Workshop on Quality, Scale and Analysis Aspects of City Models, Lund,Sweden, 2009, p. 4.

[3] M. Musio, E. A. Sauleau, and N. Augustin, "Resources allocation in healthcare for cancer: a case study using generalised additive mixed models," Geospatial Health, vol. 7, pp. 83-89, 2012

[4] L. C. Galvão, A. G. N. Novaes, J. E. Souza de Cursi, and J. C. Souza, "A multiplicatively-weighted Voronoi diagram approach to logistics districting," Computers \&amp; Operations Research, vol. 33, pp. 93114, 2006.

[5] F. Ricca and B. Simeone, "Local search algorithms for political districting," European Journal of Operational Research, vol. 189, pp. 1409-1426, 2008.

[6] S. J. D'Amico, S.-J. Wang, R. Batta, and C. M. Rump, "A simulated annealing approach to police district design," Comput. Oper. Res., vol. 29, pp. 667-684, 2002.

[7] M. Fogue, P. Garrido, F. J. Martinez, J.-C. Cano, C. T. Calafate, and P. Manzoni, "A novel approach for traffic accidents sanitary resource allocation based on multi-objective genetic algorithms," Expert Systems with Applications, vol. 40, pp. 323-336, 2013.

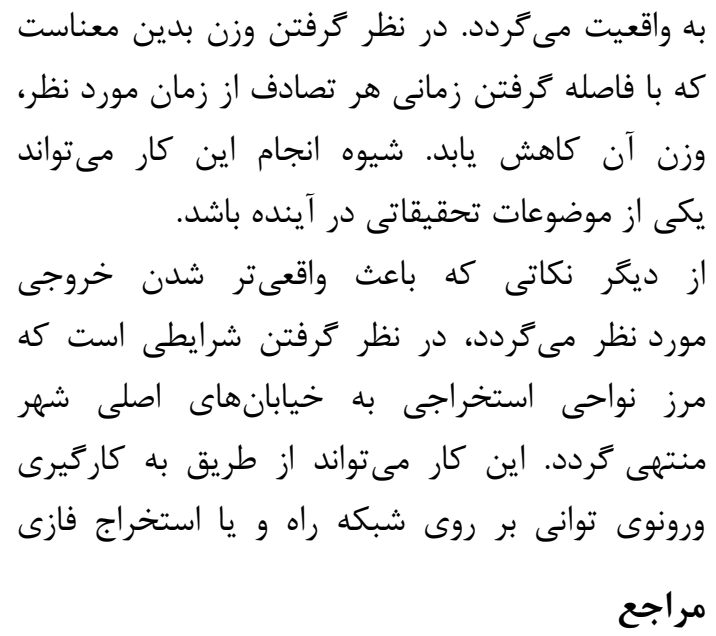

[8] G. F. Voronoi, "Nouvelles applications des parametres continus a la theorie des formes quadratiques," J. Reine u. Angew. Math., vol. 34, pp. 198-287, 1908.

[9] B. N. Boots and A. Getis, Point pattern analysis, illustrated ed.: Sage Publications, 1988.

[10] A. Okabe and M. Kitamura, "A Computational Method for Market Area Analysis on a Network," Geographical Analysis, vol. 28, pp. 330-349, 1996.

[11] A. Okabe and K.-i. Okunuki, "A Computational Method for Estimating the Demand of Retail Stores on a Street Network and its Implementation in GIS," Transactions in GIS, vol. 5, pp. 209-220, 2001.

[12] Y. Levin and A. Ben-Israel, "A heuristic method for large-scale multi-facility location problems," Computers \&amp; Operations Research, vol. 31, pp. 257-272, 2004.

[13] I. Lee and J. Yang, "Voronoi-based topological information for combining partitioning and hierarchical clustering," in Computational Intelligence for Modelling, Control and Automation, 2005 and International Conference on Intelligent Agents, Web Technologies and Internet Commerce, International Conference on, 2005, pp. 484-489.

[14] K. Liao and D. Guo, "A Clustering-Based Approach to the Capacitated Facility Location Problem1," Transactions in GIS, vol. 12, pp. 323-339, 2008.

[15] L. Liu, S. Fong, and A. Ip, "Grid-based 
hierarchical clustering for spatial resource allocation," in IADIS International Conference e-Society 2011, 2011, pp. 513517.

[16] J. Besag and J. Newell, "The Detection of Clusters in Rare Diseases," Journal of the Royal Statistical Society. Series A (Statistics in Society), vol. 154, pp. 143-155, 1991.

[17] A. B. Lawson, Statistical methods in spatial epidemiology: Wiley, 2006.

[18] B. D. Ripley, "The Second-Order Analysis of Stationary Point Processes," Journal of Applied Probability, vol. 13, pp. 255-266, 1976.

[19] R. L. O'Driscoll, "Description of spatial pattern in seabird distributions along line transects using neighbour K statistics," Marine Ecology Progress Series, vol. 165, pp. 81-94, May 07, 19981998.

[20] A. Okabe and I. Yamada, "The K-Function Method on a Network and Its Computational Implementation," Geographical Analysis, vol. 33, pp. 271-290, 2001.

[21] I. Yamada and J.-C. Thill, "Local Indicators of Network-Constrained Clusters in Spatial Point Patterns," Geographical Analysis, vol. 39, pp. 268-292, 2007.

[22] K. Sugihara, A. Okabe, and T. Satoh, "Computational method for the point cluster analysis on networks," GeoInformatica, vol. 15, pp. 167-189, 2011.

[23] M. L. Yiu and N. Mamoulis, "Clustering objects on a spatial network," presented at the Proceedings of the 2004 ACM SIGMOD international conference on Management of data, Paris, France, 2004. 


\title{
A New Approach for Allocating Dynamic Resources on Road Network by Applying Spatiotemporal Clustering of Events
}

Mohsen Goodarzi ${ }^{1}$, Farshad Hakimpour ${ }^{* 2}$, Parham Pahlavani ${ }^{3}$, Seyed Mahmood Hajimirrahimi ${ }^{4}$

1- GIS MSc, School of Surveying and Geospatial Engineering, University of Tehran, Iran

2- Assistant professor, School of Surveying and Geospatial Engineering, University of Tehran, Iran

3- Assistant professor, School of Surveying and Geospatial Engineering, University of Tehran, Iran

4- GIS\&RS MSc, Earth Science Department, Tabriz University, Iran

\begin{abstract}
A location-Allocation problem consists of two parts: locating resources and allocating them due to demands. Urban managers in order to plan metropolises, utilize various methods like districting urban regions, which is the result of solving a LA problem. Changing in urban districts, originates from dynamism rate of demands. Some efforts have been conducted to relate clustering to LA. Most of these researches apply clustering as a tool in locating resources whereas facing with dynamic demands is diminishing the importance of locating rather than allocating part. In this article the proposed method suggested dynamic location for resources in order to allocating them to the plea. The advantage of proposed method, which is a combination of statistical local K-function and non-statistical hierarchical clustering methods, lies in division of urban region into correlated and non-correlated parts. In order to deploy local K-function, Monte Carlo simulation has been applied. The Correlated and non-correlated parts are being constituted by local k-function in wide-extend; in continue they should shrink using hierarchical method. The small clusters should meet two conditions: 1) consuming accident experts' capacity as much as possible 2) not overrunning duration of reaching accident experts to collision places from a standard quantity. Evaluations show a considerable efficiency in weekdays except midnight hours. However, deploying just hierarchical method on weekends and midnight hours leads to better efficiency and also reduction in number of accident experts.
\end{abstract}

Key words: Clustering, Location-Allocation, Accidents, K-function, Hierarchical

Correspondence Address: School of Surveying and Geomatics Engineering,College of Engineering, University of Tehran,North Kargar, Tehran 1439957131.Tel: +98 2161114520 .

Email: fhakimpour@ut.ac.ir 